\title{
Pyrrolo[1,2-b]pyridazines. A revisit
}

Florea Dumitraşcu* and Dan George Dumitrescu

Center for Organic Chemistry C.D. Nenitescu, Romanian Academy 202 B, Spl. Independentei, 060023, Bucharest, Romania

E-mail:fdumitra@yahoo.com

\begin{abstract}
Although a relatively simple system, pyrrolo[1,2- $b]$ pyridazines have been subject to numerous studies and synthetic attempts. The present review represents an update to the 1976 review of Kuhla and Lombardino.
\end{abstract}

Keywords: Pyrrolo[1,2-b]pyridazine

\section{Table of Contents}

1. Synthesis of Pyrrolo[1,2-b]pyridazines

1.1. Syntheses starting from pyridazine and its derivatives

1.1.1. From pyridazine and acetylenic esters

1.1.2. The Chichibabin reaction

1.1.3. From pyridazines and cyclopropenones

1.1.4. From pyridazines and alkylidene-cyclopropane

1.1.5. From oxazolo[3,2-b]pyridazine and nucleophilic reagents

1.1.6. From 3-chloropyridazines using the Sonogashira reaction

1.1.7. The reaction of Reissert compounds with DMAD

1.1.8. The intramolecular cyclization of tetrahydro-3 $(2 H)$ pyridazinones

1.1.9. The 1,3-dipolar cycloaddition of mesoionic oxazolo[3,2-b]pyridazines

1.1.10. The 1,3-dipolar cycloaddition of pyridazinium N-ylides to olefinic and acetylenic dipolarophiles

1.1.11. From pyridazines and cyclic olefines

1.1.12. From pyridazines and spirocyclopropenes

1.2. Syntheses starting from pyrrole and its derivatives

1.3. Syntheses through rearrangement reactions

1.4. Syntheses from acyclic compounds

1.4.1. The condensation of 1,4,7-triketones with hydrazine hydrate 
1.4.2. The intramolecular [4+2] cycloaddition of azoalkenes

1.4.3. From cyanacetic acid hydrazide and 2-phenyl-1,1,3-tricyano-3-bromo-2-propene

2. Chemical Properties

2.1. Substitution reactions

2.2. Protonation and deuteration

2.3. Pyrrolopyridazine hydrogenation

2.4. Transformation of the functional groups

3. Physico-chemical and Biological Properties

\section{Introduction}

Pyrrolo[1,2-b]pyridazine $\mathbf{1}$ is a N-bridgehead aromatic heterocycle containing two nitrogen atoms, formally obtained by the condensation of pyridazine and pyrrole. The numbering of the atoms from the pyrrolo[1,2-b]pyridazine scaffold, also known in literature as 5-azaindolizine, is presented in Formula 1.

Although the synthesis and properties of the pyrrolo[1,2-b]pyridazines were reviewed in 1977 by Kuhla and Lombardino, ${ }^{1}$ the high interest in the synthetic pathways leading to such derivatives and their properties has remained constant to this date. Thus, new papers were published concerning the synthesis and optical and biological properties of pyrrolo[1,2b]pyridazine derivatives.

Herein we present the approaches for the obtaining of the pyrrolo[1,2-b]pyridazine system and its uses reported after Kuhla and Lombardino's review. ${ }^{1}$ The same classification of the synthetic methods was used as in the first review, considering the starting compounds: syntheses starting from pyridazine and its derivatives, syntheses starting from the pyrrole ring and syntheses starting from acyclic compounds.

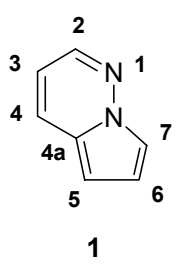




\section{The Synthesis of Pyrrolo[1,2-b]pyridazines}

\subsection{Syntheses starting from pyridazine and its derivatives}

1.1.1. From pyridazine and acetylenic esters. The first pyrrolo[1,2-b]pyridazine derivatives 3a,b were synthesized in yields of $27 \%$ and $25 \%$, respectively, by Letsinger and Lasco as long ago as 1956.

Aiming at this scaffold as a component of thin-film electroluminescent devices, Wudl et al. ${ }^{3}$ used this synthesis to obtain compounds $\mathbf{3} \mathbf{a}, \mathbf{b}^{3}$ and the novel compound $\mathbf{3} \mathbf{c}^{4}$ in $22 \%$ yield starting from 3-phenylpyridazine and DMAD. The yields for compounds 3a-c were comparable to those reported by Letsinger and Lasco. ${ }^{2}$

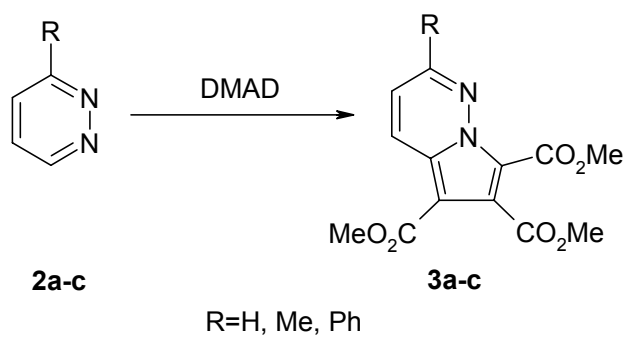

\section{Scheme 1}

Using the same type of reaction, three series of pyrrolopyridazines $\mathbf{3 d - f}$ bearing aryl moieties grafted on the 2 position directly or by a vinylic or acetylenic linker. ${ }^{5}$

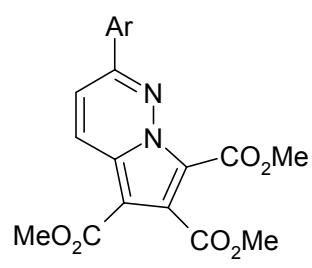

$3 d$



$3 e$



$3 \mathbf{f}$

\section{Scheme 2}

This reaction was described for the first time by Diels and Meyer in 1934 as a method for obtaining indolizines 4 starting from DMAD and pyridine and its derivatives. ${ }^{18}$ 


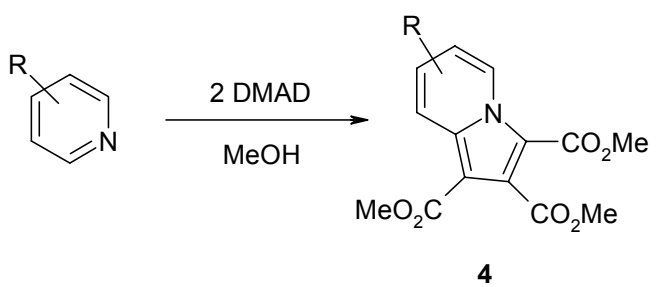

\section{Scheme 3}

Acheson and Foxton, ${ }^{19}$ while reinvestigating the reaction between pyridazine and DMAD, found that the structure of the products is dependent on the solvent. Thus, in the case of a protic solvent, such as methanol, pyrrolopyridazines are obtained, while when using acetonitrile as reaction medium, the pyridinopyridazine derivative $\mathbf{5}$ is obtained.

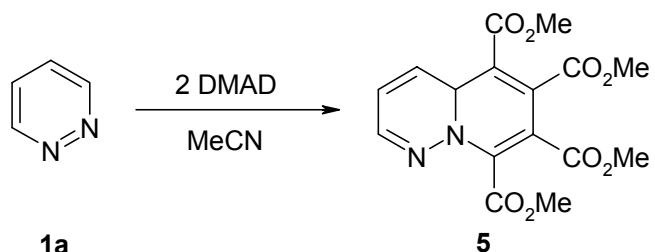

\section{Scheme 4}

The mechanism of formation of the pyrrolopyridazine derivatives presented in Scheme 1, implies in the first step the nucleophilic addition of the ring nitrogen atom to the triple bond with the formation of a zwitterionic intermediate, which fixes the proton provided by methanol, afterwards the methoxide ion generates a new dipolar species. One of the resonance structures, a 1,5-dipole, attacks intramolecularly the $\alpha$ carbon in regard to the ring nitrogen, leading to the closing of a pyrrolidinic ring, which is subsequently aromatized by elimination reactions of certain molecular fragments.



\section{Scheme 5}


The reaction between nitrogen containing aromatic heterocyles and acetylenic esters, the most effective being DMAD, was successfully used to synthesize a wide range of new heterocyclic systems difficult or impossible to obtain via other synthetic means. ${ }^{6-17}$

1.1.2. The Chichibabin reaction. The Chichibabin reaction ${ }^{20-23}$ is one of the general synthetic methods for obtaining indolizines and implies the $\mathrm{N}$-alkylation of 2-substituted pyridines with an $\alpha$-halogenated carbonyl compound, followed by the intramolecular cyclization in the presence of a weak base, the most commonly used being sodium bicarbonate. The method was successfully applied for other 2-substituted nitrogen containg aromatic heterocycles.

The Chichibabin reaction was first applied for the series of pyrrolopyridazines by Letsinger and Lasco in 1956, as a means of confirming the structure of the compounds obtained from the reaction between DMAD and pyridazines. ${ }^{2}$ Thus, 3,6-dimethylpyridazine was quaternized with ethyl bromopyruvate, and the treatment of the cycloimmonium bromide formed with sodium bicarbonate lead to the ethylic ester of the pyrrolo[1,2-b]pyridazine-6-carboxylic acid 6 (Scheme $6)$.

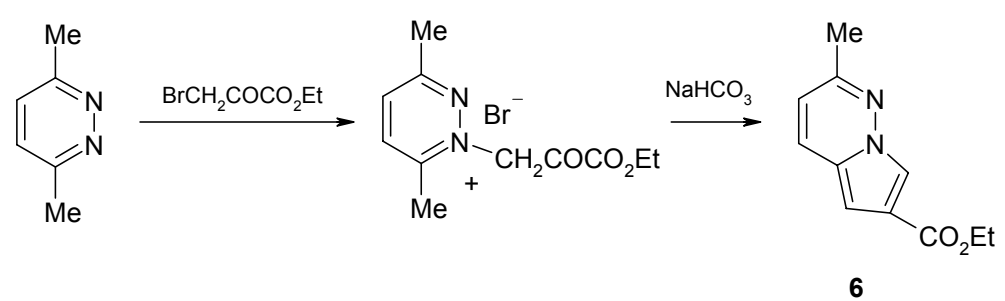

\section{Scheme 6}

Fraser synthesized a series of pyrrolopyridazines 7, substituted in the 6 and 7 positions by alkyl and/or aryl groups, starting from 2-halogenoketones and 3,6-dimethylpyridazine (Scheme 7). ${ }^{24,25}$

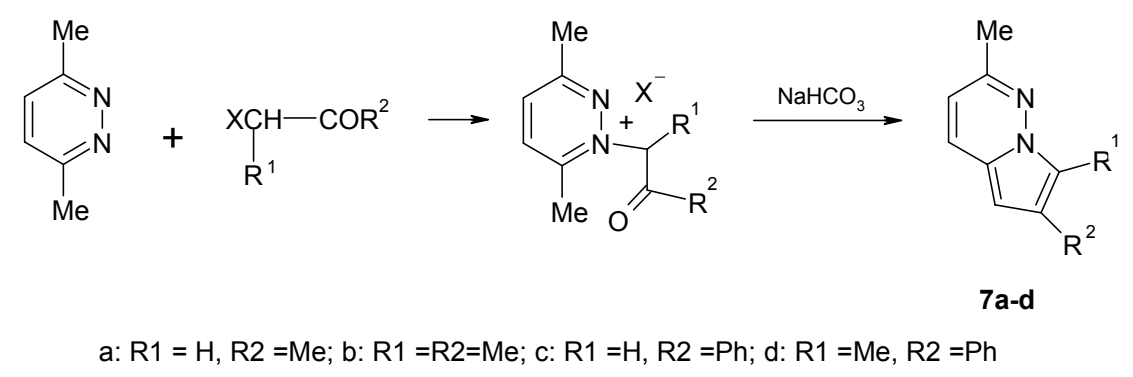

\section{Scheme 7}


When using 3-methyl-6-methoxy pyridazine and bromoacetone in the Chichibabin reaction, was obtained 2-methoxy-6-methyl-pyrrolo[1,2-b]pyridazine 8, which under the action of bromhidric acid lead to pyrrolo[1,2-b]pyridazine-6(5H)-one 9 (Scheme 8$).{ }^{26}$

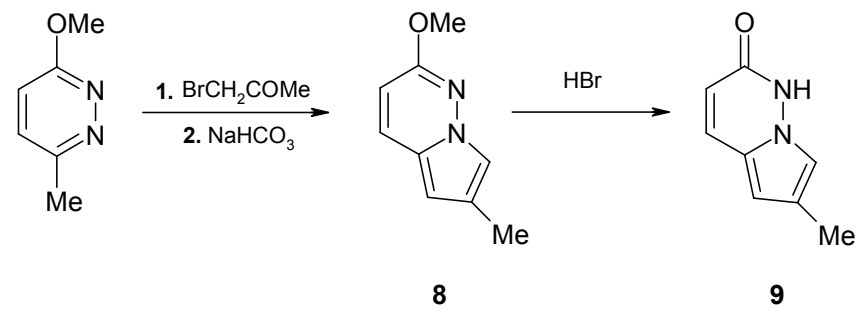

\section{Scheme 8}

1.1.3. From pyridazines and cyclopropenones. Lown and Matsumoto studied the reaction between diphenyl-cyclopropenone and various $N$-heterocyclic aromatic compounds. ${ }^{27,28}$ Thus, starting from pyridazine and diphenyl-cyclopropenone, 5,6-diphenyl-7-hydroxy-pyrrolo[1,2b]pyridazine $\mathbf{1 0}$ is obtained in about 70\% yield (Scheme 9). The structure of the cycloadduct $\mathbf{1 0}$ was ascertained mainly by the NMR data for hydroxy-indolizine and its chemical transformation products. After twenty years, a group of American scientists reinvestigated the reaction of diphenyl-cyclopropenone with pyridazine and other azines. ${ }^{29-31}$ Starting from inconsistencies between various physical properties (melting point, NMR data) of the obtained compounds and those reported by Lown and Matsumoto, it was postulated that the initially assumed structures were incorrect. Thus, NOE experiments performed on the hydroxy-indolizine acetates showed that the hydroxy group is in the 5 position. The same observation was made for the hydroxypyrrolopyridazine acetate $\mathbf{1 2}$.

Also, when 3-methylpyridazine reacts with diphenylcyclopropenone, the pyrrolopyridazine derivative 11b is obtained in good yields (Scheme 11). For the product formed in the reaction between cyclohepten-cyclopropenone and pyridazine, structure 10c was assigned (Scheme 10).

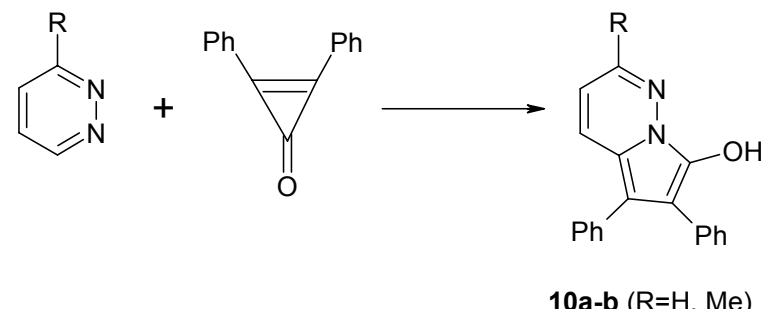

\section{Scheme 9}




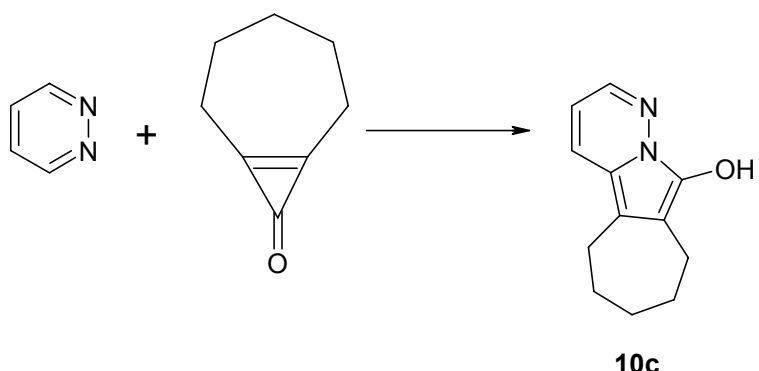

Scheme 10

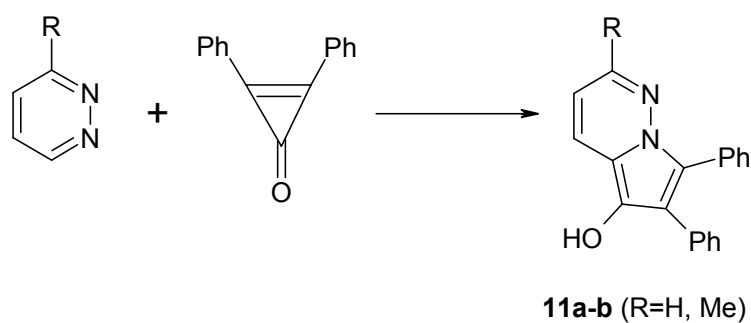

\section{Scheme 11}

By treating compound 11a with acid chlorides, anhydrides, alkyl halides, chloroformiates, isocyanates etc. ${ }^{31-34}$ pyrrolopyridazine derivatives 12 were synthesized.

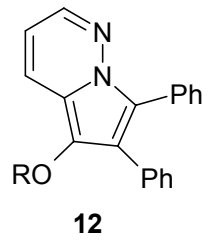

$\mathrm{R}=\mathrm{Me}, \mathrm{Et}, \mathrm{MeCO}, \mathrm{MeOCO}, \mathrm{CF}_{3} \mathrm{SO}_{2}, \mathrm{PhNHCO}$ etc

\section{Scheme 12}

The study of the biological activity of compounds 11, 12, as well as of those obtained starting from pyridines and diphenylcyclopropenone, showed a strong inhibition of the peroxidation of lipids in vitro for some of the studied derivatives. This recommends their usage as potential antioxidants for pathological processes which imply free radicals. ${ }^{32-34}$

1.1.4. From pyridazines and alkylidene-cyclopropane. ${ }^{35}$ The synthesis of 5 -azaindolines starting from 1,2-diazines and alkylidenecyclopropane has been considered, as in the case of the reaction between azines and diphenylcyclopropenone, a formal cycloaddition $[3+2] .{ }^{35}$ Thus, in the reaction between pyridazine and akylidenecyclopropane $\left(\mathrm{R}^{1}, \mathrm{R}^{2}=\right.$ alkyl) without solvent and 
in the presence of a $\mathrm{Pd}$ catalyst, 5-alkyl substituted pyrrolopyridazines $\mathbf{1 3}$ are obtained in moderate yields (39-49\%) (Scheme 13).

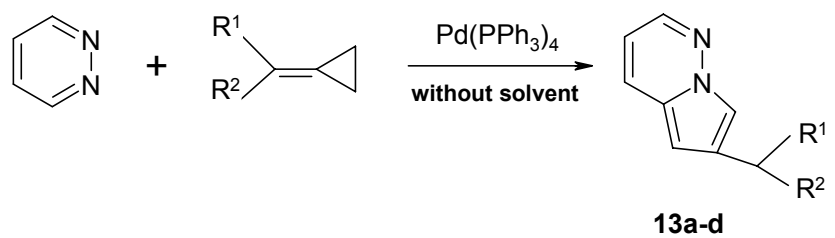

a: R1=R2 =Bu; b: R1=R2 =hexyl; c: R1 =hexyl, R2 =propyl; d: R1= pentyl, R2 =Et

\section{Scheme 13}

1.1.5. From oxazolo[3,2-b]pyridazine and nucleophilic reagents. ${ }^{36}$ Pyrrolopyridazine derivatives 17-19 were synthesized in good yields from the reaction between oxazolo[3,2$b]$ pyridazine perchlorates $\mathbf{1 6}$ and the sodium salts of malonitrile, malonic ester and ethyl cyanoacetate, respectivly. The mechanism of formation of compounds 17-19 implies the nucleophilic addition at position 8 a of the cation 16, followed by the opening of the oxazolic ring and the subsequent recyclization to the corresponding pyrrolopyridazines (Scheme 15). Perchlorates 16 were obtained by the $N$-alkylation of 3(2H)pyridazinones 14 with an $\alpha$ halogenoketone, followed by cyclization in sulfuric acid medium in the presence of sodium perchlorate (Scheme 14).

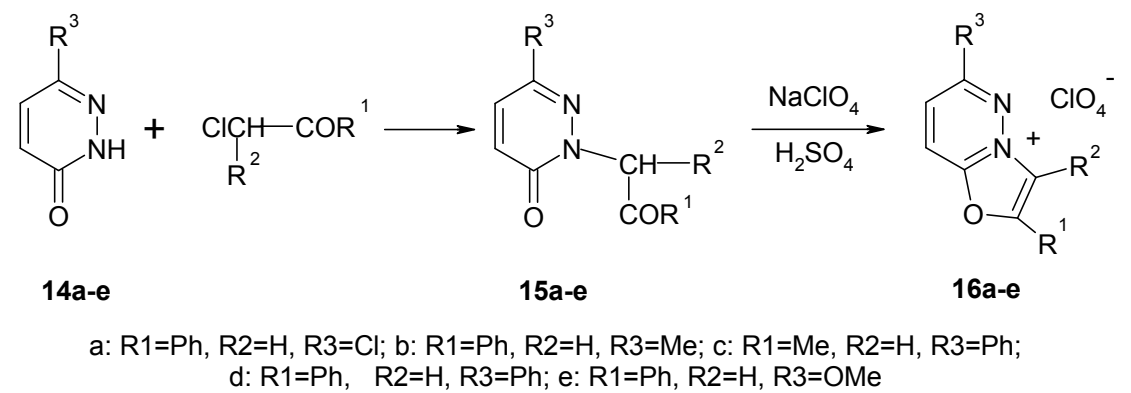

\section{Scheme 14}




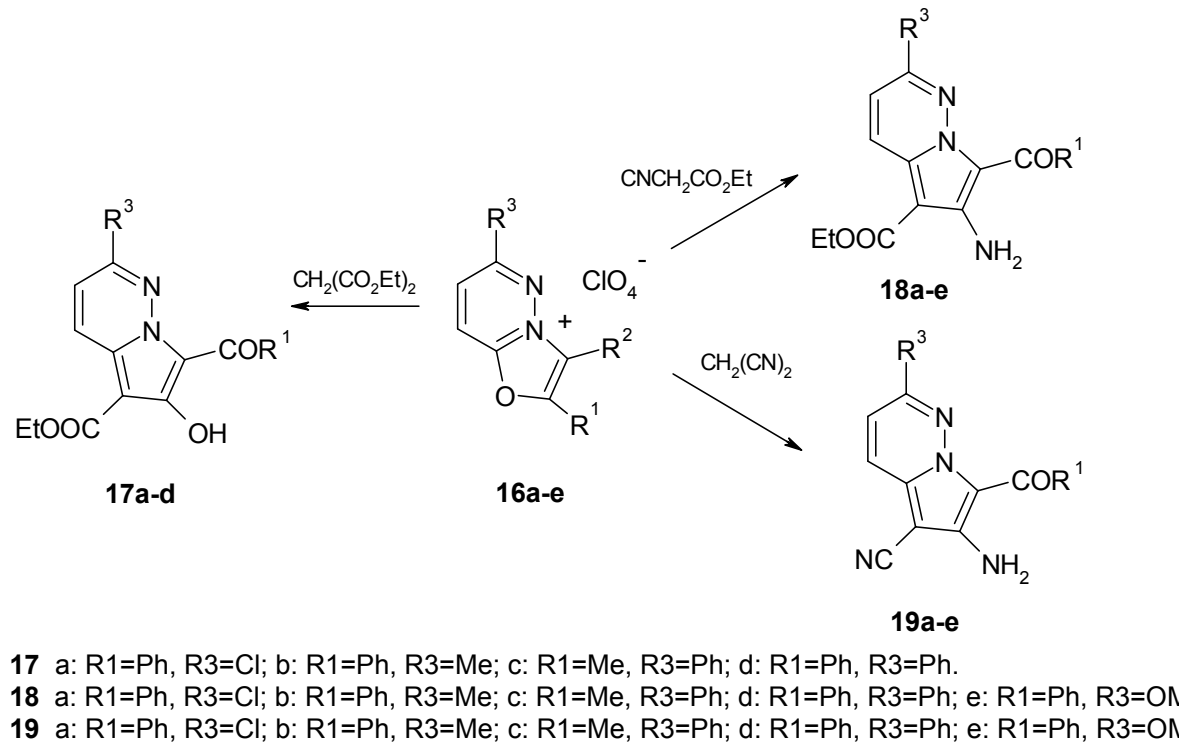

\section{Scheme 15}

1.1.6. From 3-chloropyridazines using the Sonogashira reaction. ${ }^{37,38}$ 7-Dialkylaminopyrrolo[1,2-b]pyridazines 22a-e were synthesized by the "one-pot" reaction of 3chloropyridazines 20a-c with propargyl alchohol, followed by cyclization with dialkyl amines, in the presence of $\mathrm{Pd}\left(\mathrm{PPh}_{3}\right) \mathrm{Cl}_{2}-\mathrm{CuI}$ as catalyst. The yields for the pyrrolopyridazine derivatives were found to be in the range of $13-49 \%$. It is very likely that the reaction mechanism for the formation of compounds $\mathbf{2 2}$ is the same as in the case of using pyridine derivatives as starting materials. This mechanism implies in the first stage the alkynylation of the C-3 atom via a Sonogashira coupling. The second stage consists of the condensation with diethylamine and subsequent cyclization of 3-(2-pyridyl)acrolein, which in turn is obtained from the isomerization and tautomerization of 3-(2-pyridyl)propyn-1-ol in basic conditions (Scheme 16).



\section{Scheme 16}


1.1.7. The reaction of Reissert compounds with DMAD ${ }^{39}$ Reissert compounds formally results from the addition of a ketone group to the nitrogen atom and of a cyano group to the carbon atom from the $\mathrm{C}-\mathrm{N}$ bond in compounds such quinoline, isoquinoline and other heterocycles. ${ }^{40-47}$ Popp et al. ${ }^{39}$ obtained the Reissert compound of 3-methylpyridazine using as reagents trimethylsilyl cyanide and freshly distilled benzoyl chloride. The reaction of pyridazine and 3methylpyridazine with undistilled benzoyl chloride lead to the Reissert compound salts 24a,b. Compound 24a forms with DMAD in anhydrous DMF pyrrolopyridazine derivative 25 (Scheme 17).

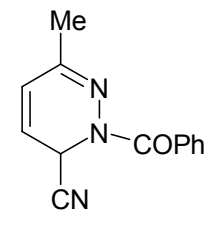

23



24a,b<smiles>CC(=O)c1c(C(C)=O)c2cccnn2c1-c1ccccc1</smiles>

25

\section{Scheme 17}

1.1.8. The intramolecular cyclization of hexahydro-3(2H)pyridazinones. ${ }^{48}$ Masanori et al. ${ }^{48}$ synthesized 3,4,5,6-octahydro-pyrrolo[1,2-b]pyridazine-2,7-dione $\mathbf{2 8}$ starting from diethyl 4oxopimelate and 3,4-dimethoxyphenethyl-hydrazine which condense into 4,5-dihydro-3(2H)pyridazinone 26. The catalytic reduction of endocyclic $\mathrm{C}-\mathrm{N}$ double bond leads to the tetrahydropyridazinone derivative $\mathbf{2 7}$ which undergoes intramolecular cyclization, resulting in compounds 28 (Scheme 18). Although only one example of pyrrolopyridazine synthesis starting from oxopimelate and hydrazines is known, analogues of compound 26 with methyl ${ }^{49}$ or phenyl ${ }^{50}$ as substituents of the lactamic nitrogen atom. These intermediaries may be used as precursors for the preparation of structures similar to compound $\mathbf{2 8}$.

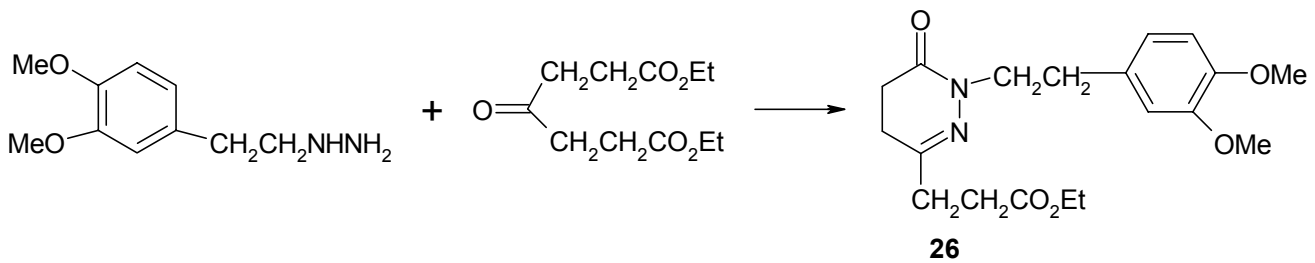



27

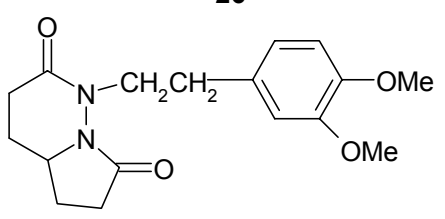

28

\section{Scheme 18}


1.1.9. The 1,3-dipolar cycloaddition of mesoionic oxazolo $[3,2-b]$ pyridazines ${ }^{51}$ One of the general synthetic methods for obtaining pyrroles and pyrroloazines having a nitrogen atom at the junction of the two heterocyclic moieties is the 1,3-dipolar cycloaddition between mesoionic 1,3oxazole-5-ones, also called munchnones, and acetylenic dipolarophiles. ${ }^{52-60}$ Recently, pyrrolo[1,2- $b$ ]pyridazine derivatives 32 were obtained in good yields, starting from pyridazinone-propanoic acids 29 and DMAD in acetic anhydride as reaction medium at $90{ }^{\circ} \mathrm{C}$. The formation of compounds 32 implies the generation of bicyclic mesoionic compounds 30, followed by a 1,3-dipolar cycloaddition with the acetylenic dipolarophile resulting in unstable intermediaries 31, which stabilize in the reaction conditions by eliminating a carbon dioxide molecule (Scheme 19).

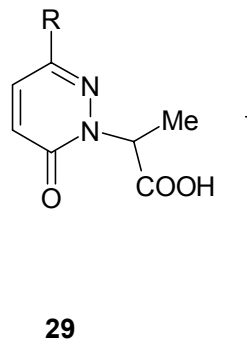

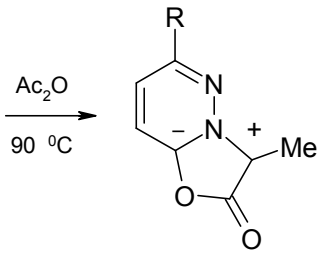

30



31

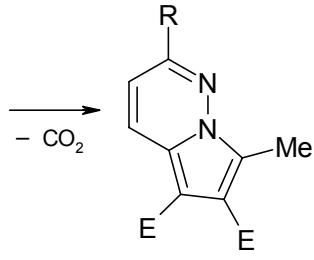

32

$\mathrm{R}=\mathrm{Me}, \mathrm{Ph}, 4-\mathrm{MeC} 6 \mathrm{H} 4,4-\mathrm{ClC} 6 \mathrm{H} 4$

\section{Scheme 19}

When starting from pyridazinone-acetic acids 33, along with unsubstituted pyrrolo[1,2$b]$ pyridazines 35, mesoionic oxazolo[3,2-b]pyridazines $\mathbf{3 6}$ are also obtained, for which structural proof was obtained by NMR data and "off-resonance" experiments (Scheme 20). The formation of compounds 36 was explained as the Michael addition of DMAD to the C-3 atom from the oxazolic ring, this type of reaction being known for other $\mathrm{N}$-aromatic heterocycles, such as pyrrole, indole etc. ${ }^{61-67}$<smiles>[R]c1ccc(=O)n(CC(=O)O)n1</smiles>

33

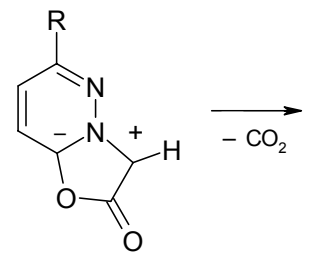

34

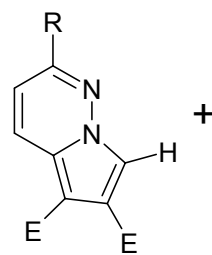

35

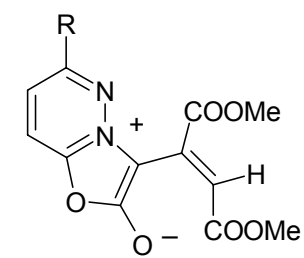

36

$\mathrm{R}=\mathrm{Me}, \mathrm{Ph}, 4-\mathrm{MeC} 6 \mathrm{H} 4,4-\mathrm{ClC} 6 \mathrm{H} 4$

\section{Scheme 20}

1.1.10. The 1,3-dipolar cycloaddition of pyridazinium $\mathrm{N}$-ylides to olefinic and acetylenic dipolarophiles. ${ }^{68-103}$ One of the most useful methods for obtaining pyrrolopyridazine derivatives is the 1,3-dipolar cycloaddition between pyridazinium $N$-ylides and activated olefinic or 
acetylenic dipolarophiles. The synthesis of pyrrolo[1,2-b]pyridazines through 1,3-dipolar cycloadditions has been described in over 35 papers, using acetylenic, ${ }^{68-80}$ olefinic, ${ }^{80-92}$ as well as both acetylenic and olefinic dipolarophiles. ${ }^{93-103}$ The advantages of the method consist of: a) the availability of the raw material, as pyridazinium salts are easily obtained from pyridazine or its derivatives and halogenated derivatives, and b) the pyridazinium $\mathrm{N}$-ylide generation and the cycloaddition are performed "one-pot", and the cycloaddition does not require special reaction conditions.

The first synthesis of a pyrrolopyridazine derivative through the reaction between a pyridazinium $N$-ylide and an acetylenic dipolarophile (DMAD) was reported in 1967 by Farnum and co-workers. ${ }^{6}$

Heteroaromatic $N$-ylides can be classified by the substitution degree at the exocyclic carbanion as unsubtituted, monosubstituted and disubstituted. In [3+2] cycloadditions pyridazinium methanide $\left(\mathrm{R}^{1}=\mathrm{H}\right) \mathbf{3 7},{ }^{69}$ pyridazinium carbanion monosubstituted $\mathbf{3 8}$ and carbanion disubstituted $39 \mathrm{~N}$-ylides ${ }^{70-73,97-99}$ were used as dipolarophiles (Scheme 21). The yields of the pyrrolopyridazines depend on the following factors: the reactivity and stability of the ylide and the reactivity of the dipolarophile. Therefore, pyridazinium-methanide $37\left(\mathrm{R}^{1}=\mathrm{H}\right)$, although with a high reactivity due to instability, reacts only with DMAD with an yield in pyrrolopyridazine below $10 \%{ }^{69}$

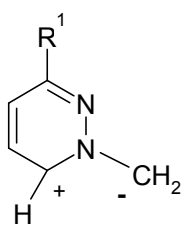

37

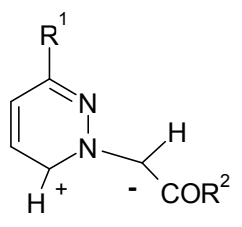

38

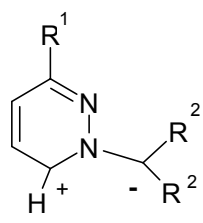

39

\section{Scheme 21}

Good yields for pyrrolopyridazine derivatives are obtained when symmetrical esters of acetylene dicarboxylic acid or esters of acetylene monocarboxylic acid are used as dipolarophiles and when the N-ylide is monosubtituted at the carbanion with an alkoxycarbonyl, aroyl or heteroaroyl moiety (Scheme 21). Most probably these groups stabilize the ylidic dipole sufficiently for it to react with the acetylenic dipolarophile. When the acetylenic dipolarophile is insufficiently active in order to react with N-ylides of type 38, low yields are obtained, as the Nylide decomposition and dimerization rates are higher than that of the $[3+2]$ cycloaddition.

The mechanism of formation of pyrrolo[1,2]pyridazines from N-ylides and acetylenic esters (Scheme 22) implies in the first step the formation of the primary cycloadduct 40, which isomerizes to $4 \mathrm{a}, 5$-dihydro-pyrrolo[1,2]pyridazine $\mathbf{4 1}$ in the reaction conditions. Although the formation of 4a,7-dihydroderivatives of type $\mathbf{4 0}$ has been mentioned in many papers, no data was presented for the presence of these compound, as opposed to the case of phtalazinium $\mathrm{N}$ ylides. ${ }^{104}$ Finally, the dihydroderivative is aromatized in the reaction conditions, but in some 
cases mixtures of dihydropyrrolopyridazine $\mathbf{4 1}$ and aromatic compound $\mathbf{4 2}$ were obtained. The addition of an oxidizing agent after the completion of the cycloaddition, such as chloranil, results in an increase of the yield. ${ }^{69}$ Microwave assisted cycloaddition between pyridazinium N-ylides and methyl propiolate ${ }^{102}$ does not significantly improved the yield, as similar results were obtained in the absence of microwaves. ${ }^{79}$
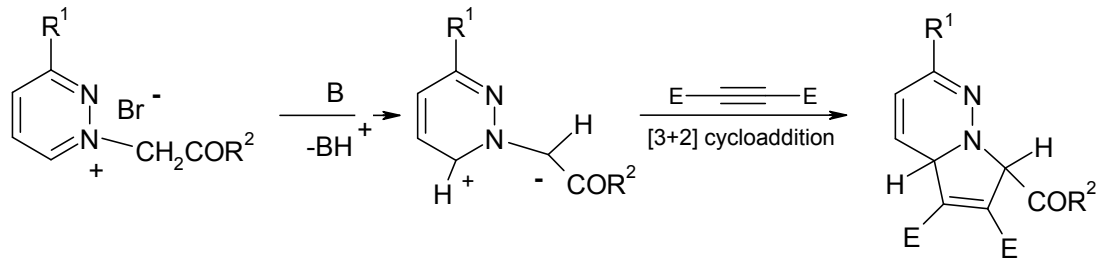

38

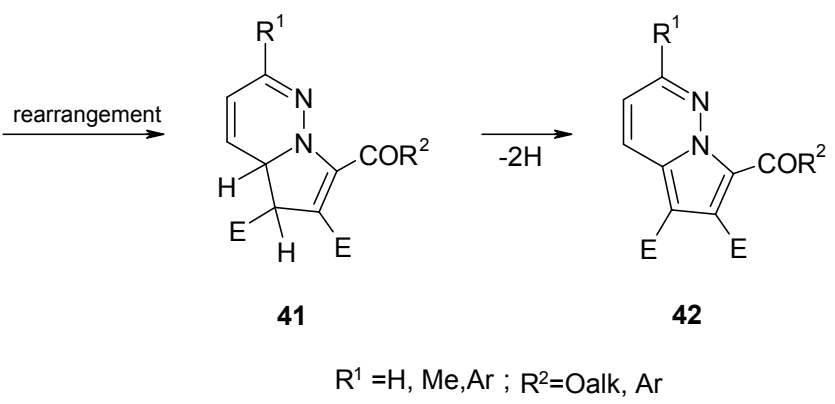

\section{Scheme 22}

Among the disubstituted N-ylides at the exocyclic carbanion 39, the [3+2] cycloadditions of pyridazinium-dicyanomethanide and some of its derivatives with various dipolarophiles with double or triple bond. ${ }^{70-72,97-99}$ It must be mentioned that pyridazinium dicyanomethylides $\mathbf{3 9}$ are very stable $\mathrm{N}$-ylides, which translates into the ability to react with low reactivity acetylenic dipolarophiles, such as bis(trimethylsilyl) acetylene. The preparation of dicyanomethylides 39a-f was performed using the method described by Linn et al. ${ }^{105}$ from pyridazines and tetracyanoethylene oxide(Scheme 23).

The cycloaddition between ylides 39a-f and DMAD leads to 7-cyano-pyrrolopyridazines $\mathbf{4 4}$, which result from the intermediate cycloadducts $\mathbf{4 3}$ through the elimination of a cyano group from the 7 position together with the $\mathrm{R}^{3}$ group. In the case of reacting ylids 39a, 39b and 39d with cyanoacetylene, 5,7-dicyano-pyrrollopyridazines substituted in the 5 position with a hydrogen, methoxy and ethoxy group, respectively (Scheme 24). ${ }^{71}$ At the same time, another group of researchers ${ }^{70}$ prepare the dicyanomethylides 39a,b and perform the cycloaddition with DMAD with the formation of the corresponding pyrrolopyridazines. 


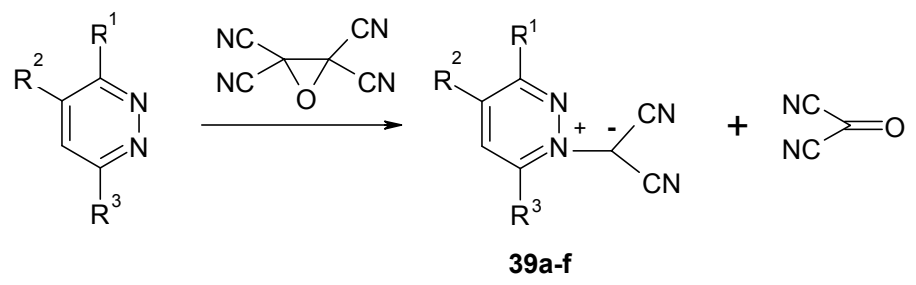

a: $\mathrm{R} 1=\mathrm{R} 2=\mathrm{R} 3=\mathrm{H} ; \mathrm{b}: \mathrm{R} 1=\mathrm{OMe}, \mathrm{R} 2=\mathrm{R} 3=\mathrm{H} ; \mathrm{c}: \mathrm{R} 1=\mathrm{R} 3=\mathrm{OMe}, \mathrm{R} 2=\mathrm{H}$ d: R1=OEt, R2=R3=H; e: R1=R3=OEt, R2=H; f: R1=R3=H, R2=Me

\section{Scheme 23}

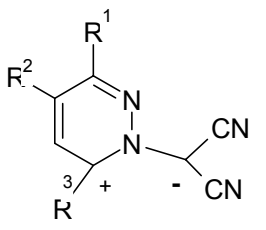

39

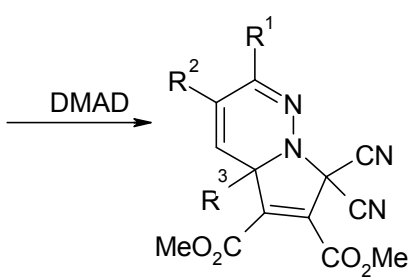

43

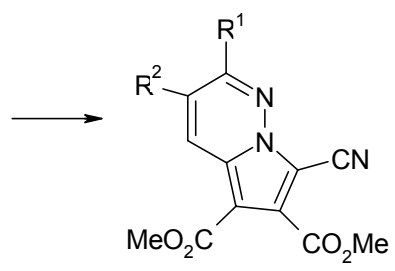

44

\section{Scheme 24}

The dicyanomethylide 39a reacts with bis(trimethylsilyl)acetylene under reflux in toluene, leading to the formation of 1,2-bistrimethylsilyl-3-cyano-pyrrolopyridazine $\mathbf{4 5}$ with $92 \%$ yield. $^{72-}$ ${ }^{97}$ In similar reaction conditions, the use of phenylsulfenyl-ethene as dipolarophile leads to 7cyano-pyrrolo[1,2-b]pyridazine 46 in $42 \%$ yield (Scheme 25). The reaction mechanism includes the dipole-dipolarophile interaction from the pyrrolidinic ring and the elimination of the cyano and phenylsulfenyl groups from the intermediary cycloadduct.


39a

46

\section{Scheme 25}

Butler et al. studied the influence of water on the kinetics and yields of the cycloadditions between pyridazinium-dicyanomethylide 39a and a series of olefinic and acetylenic 
dipolarophiles. $^{98,99}$ On the basis of numerous experiments, the authors classified the dipolarophiles in two types: "water-normal" and "water-super" and evidenced the principal factors affecting the reaction rate: hydrophobic effects which aggregate the organic compounds, the effects of hydrogen bonding on the transition state and the increase in polarity of the transition state in water. It was established that esters, ethers, sulfones and nitriles, as well as aryl cycles linked to a double bond are "water-normal" dipolarophiles, while compounds with a ketone group linked to a double or triple bond are "water-super" dipolarophiles. It should be mentioned that the authors isolated and characterized several primary cycloadducts $\mathbf{4 3}$ resulting from the dipole-dipolarophile reaction.

Ylides of type $\mathbf{3 8}$ readily react with acyclic activated olefins (acrylonitrile, acrylic, fumaric and maleic acid esters) or cyclic activated olefins (maleic anhydride, $\mathrm{N}$-substituted maileimides) leading to the tetrahydro-pyrrolopyridazine derivatives 47-51 (Scheme 26). ${ }^{81-103}$ Literature data indicates that tetrahydro-pyrrolopyridazines are relatively unstable in solution, but stable in solid state. When the cycloaddition reaction is microwave assisted, the primary cycloadduct is partially dehydrogenated or aromatized. ${ }^{102}$ The stereochemistry of these cycloadducts was established using NMR spectroscopy and in a single case X-ray diffraction. ${ }^{89}$ The cycloaddition reaction between pyridazinium $\mathrm{N}$-ylides and non-symmetrical olefinic dipolarophiles is completely regioselective in the case of ylides substituted at the carbanion by a COAr radical. However, it was observed that when the COAr radical is replaced by $\mathrm{R}^{2}=\mathrm{CO}_{2} \mathrm{Me}$ radical, both regiomers $\mathbf{5 0}$ and $\mathbf{5 1}$ are formed. ${ }^{89}$

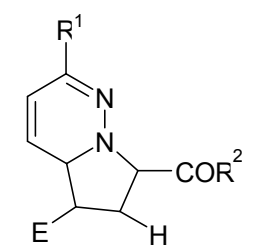

47

$\left(\mathrm{E}=\mathrm{CN}, \mathrm{CO}_{2} \mathrm{Et}\right)$



48

cis/trans

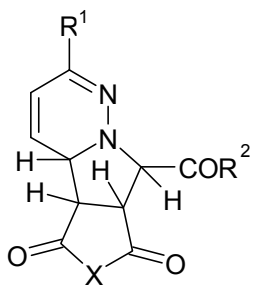

49

$\mathrm{X}=\mathrm{O} ; \mathrm{NR}$

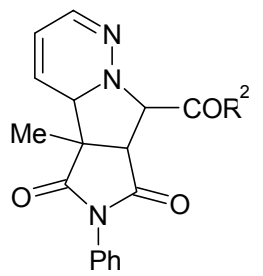

50

$\mathrm{R}^{2}=\mathrm{Ar}, \mathrm{OMe}$

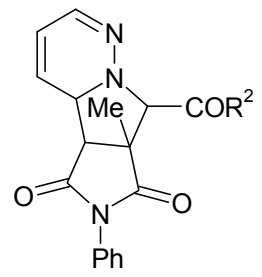

51

$\mathrm{R}^{2}=\mathrm{OMe}$

\section{Scheme 26}

The aromatization of tetrahydro-pyrrolopyridazines of type 47, 48 to pyrrolopyridazines 52 was performed using tetrakispyridino-cobalt(II) dichromate (TPCD), $\left[\mathrm{Co}(\mathrm{Py})_{4}\right]\left(\mathrm{HCrO}_{4}\right)_{2}$, as oxidizing agent. ${ }^{106,107}$ This oxidizing agent was widely used for the aromatization of the cycloadducts resulted from heteroaromatic N-ylides and olefinic and even acetylenic dipolarophiles. ${ }^{108-115}$ 


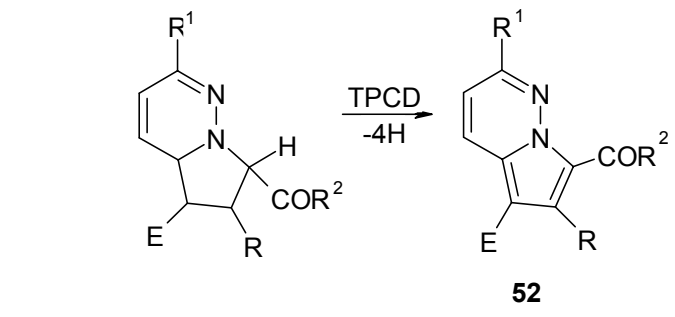

$47: \mathrm{R}^{1}=\mathrm{H}, \mathrm{Me} ; \mathrm{R}^{2}=\mathrm{Ar} ; \mathrm{E}=\mathrm{CN}, \mathrm{R}=\mathrm{H} ; 48: \mathrm{E}=\mathrm{CO}_{2} \mathrm{Et}, \mathrm{R}=\mathrm{H} ; \mathrm{E}=\mathrm{R}=\mathrm{CO}_{2} \mathrm{Et}$

\section{Scheme 27}

Zhang and Huang ${ }^{90}$ have used for the synthesis of pyrrolopyridazine derivatives $\mathbf{5 3} 2$,2dihydroperfluoroalkanoates and phenacyl pyridazinium bromide. The formation of compounds 53 implies the [3+2] cycloaddition between the pyridazinium N-ylide and the alkene, both generated in situ in the presence of a base, followed by the aromatization of the intermediary cycloadduct (Scheme 28).

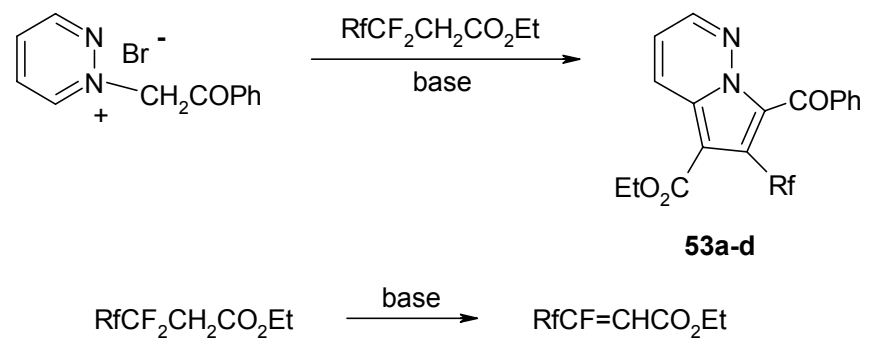

Scheme 28

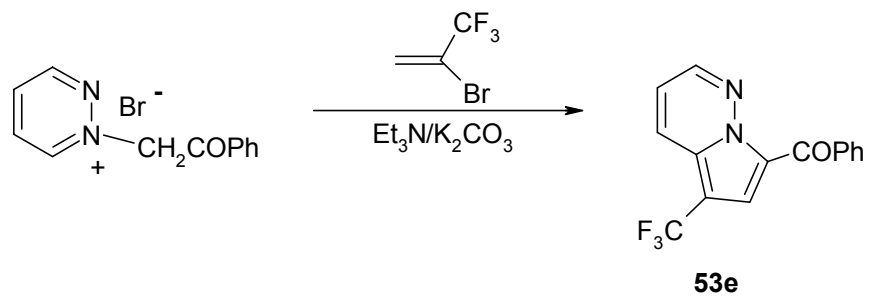

\section{Scheme 29}

Khlebnikov et al. ${ }^{91,92}$ proposed a general method for the synthesis of pyrrole-substituted pyrroloazines, which is based on the reaction between dichlorocarbene and an azine in the presence of dimethyl maleate. The reaction mechanism, shown for pyridazine, implies the in situ generation of dichlorocarbene, which forms with pyridazine the corresponding dichloromethanide. The 1,3-dipolar cycloaddition between the pyridazinium N-ylide $\mathbf{5 4}$ and dimethyl maleate leads to the tetrahydropyrrolopyridazine derivative 55, which undergoes dehydrogenation in the reaction conditions with the formation of 5,6-dicarbomethoxy-7-chloro- 
pyrrolo[1,2-b]pyridazine 56 (Scheme 30). The 7-chloro group was replaced by a 7-amino group (compound 59) through a series of reactions: the substitution of the chlorine atom with a benzylamino group with the formation of the aminoderivative $\mathbf{5 7}$, followed by the oxidation to the Schiff base $\mathbf{5 8}$ and the subsequent treatment of this with a hydrochloric acid solution in methanol.



\section{Scheme 30}

1.1.11. From pyridazines and cyclic olefins. Cookson and Isaacs established that starting from pyridazine and maleic anhydride in a 1:2 molar ratio, a compound was formed for which the hexahydropyrido-pyridazine $\mathbf{6 0}$ structure was proposed. ${ }^{116}$ On the basis of later NMR data and of various chemical transformation, it was deduced that the structures of the cycloadducts resulting from the reaction between pyridazine and maleic anhydride and $\mathrm{N}$-phenylmaleimide are of tetrahydro-pyrrolo[1,2-b]pyridazine $\mathbf{6 1 , 6 2}$ type. ${ }^{117,}{ }^{118}$ The hydrolysis through simple water reflux of adduct 61, obtained from pyridazine and maleic anhydride, results in the tetracarboxylic acid $\mathbf{6 3}$ (Scheme 31). ${ }^{118}$<smiles>O=C1OC(=O)C2C1C1C(=O)OC(=O)C1N1N=CC=CC21</smiles>

60<smiles>O=C1CC2(C(=O)O1)C1C(=O)OC(=O)C1C1C=CC=NN12</smiles>

61

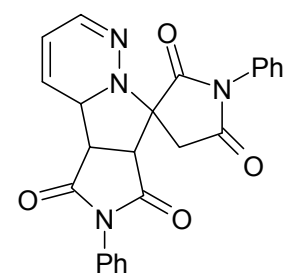

62<smiles>O=C(O)CC1(C(=O)O)C(C(=O)O)C2C=CC=NN2C1C(=O)O</smiles>

63

\section{Scheme 31}


1.1.12. From pyridazines and spirocyclopropenes. N-Aromatic heterocycles and spirocyclopropene derivatives form in etheric solution at room temperature substituted spiro1,8a-dihydroindolizines corresponding to the starting materials (Scheme 32). Spiranic compounds containing the dihydro-indolizine skeleton posses high photochromism and were subjected to intense study. ${ }^{119-134}$ Photochromism can be defined in the simplest way as a light induced reversible color change of a chemical species (Scheme 33). In Scheme 32 the formation of spiro-dihydro-pyrrolo[ $[1,2-b]$ pyridazine derivatives and the selective hydrogenation of the $\mathrm{C}=\mathrm{C}$ double bond from the pyridazinic cycle are presented. Starting from the diacetylated spirocyclopropenes and substituted pyridazines, the corresponding pyridazinopyrrolopyridazines were synthesized.

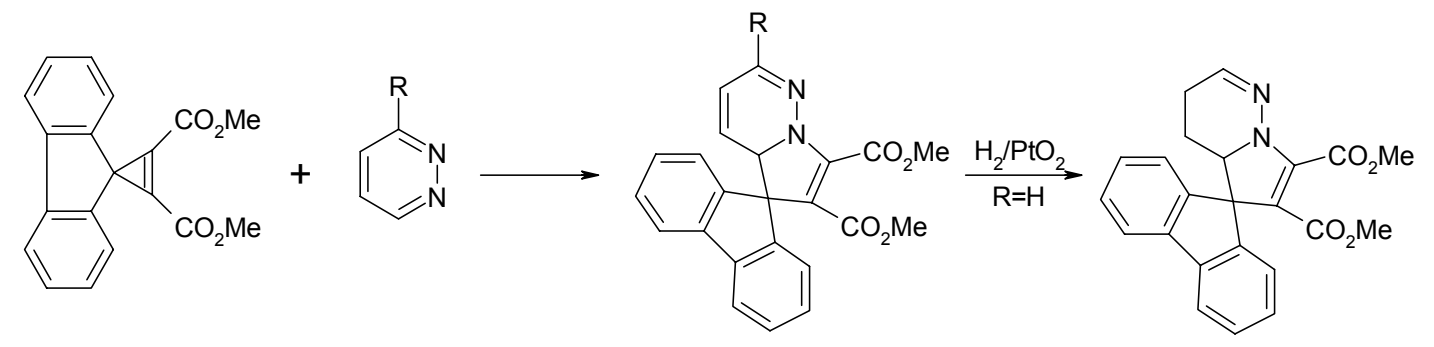

$\mathrm{R}=\mathrm{H}, \mathrm{Me}, \mathrm{CO}_{2} \mathrm{Me}$

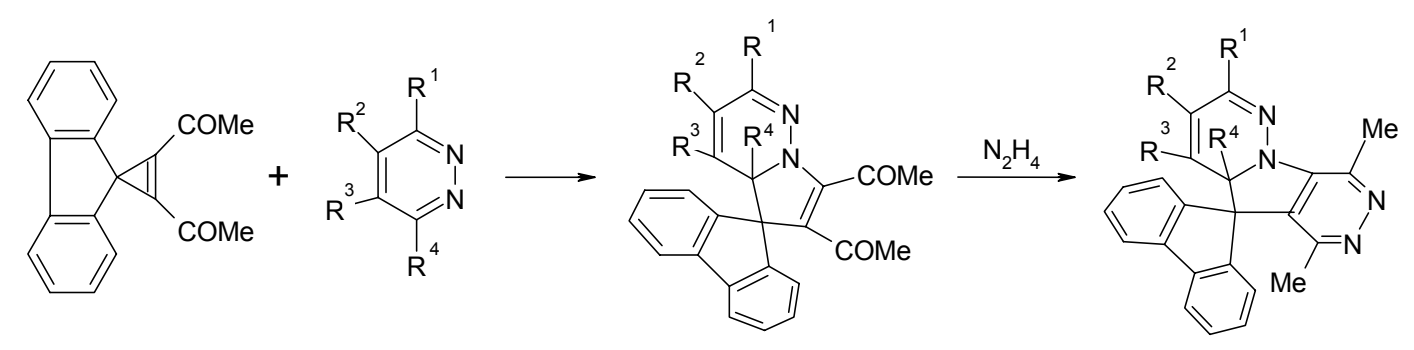

$\mathrm{R}^{1}=\mathrm{R}^{2}=\mathrm{R}^{3}=\mathrm{R}^{4}=\mathrm{H} ; \mathrm{R}^{1}=$ COOMe, $\mathrm{R}^{2}=\mathrm{R}^{3}=\mathrm{R}^{4}=\mathrm{H} ; \mathrm{R}^{1}=\mathrm{R}^{4}=\mathrm{Me}, \mathrm{R}^{2}=\mathrm{R}^{3}=\mathrm{H} ; \mathrm{R}^{1}=\mathrm{R}^{2}=\mathrm{R}^{3}=\mathrm{R}^{4}=\mathrm{Me}$

\section{Scheme 32}

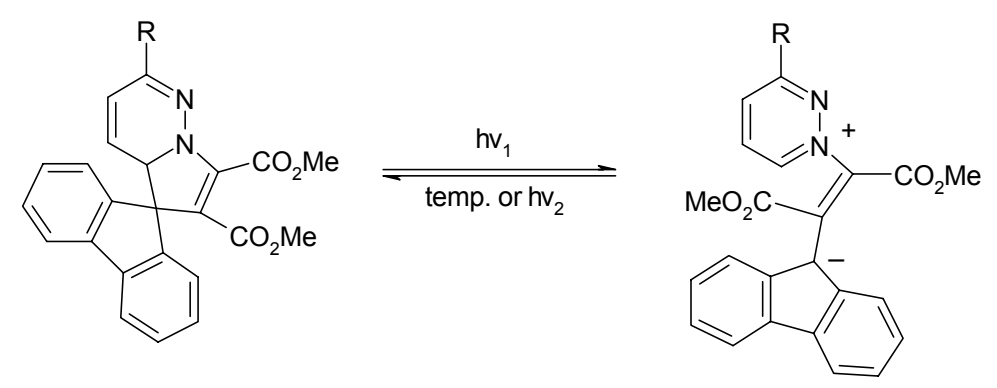

\section{Scheme 33}




\subsection{Syntheses starting from pyrrole and its derivatives}

A general method of synthesis for pyrrolo[1,2-b]pyridazine derivatives starts from 1aminopyrrole 64 and its derivatives. This original method was reported by Flitsch and Kramer ${ }^{135-}$ ${ }^{137}$ who obtained a series of pyrrole unsubstituted pyrrolopyridazines $\mathbf{6 5}$ starting from 1-aminopyrrole and $\beta$-dicarbonylic compounds (Scheme 34). Benzoylacetone, by condensation with 64, leads to only one isomer, 2-methyl-4-phenyl-pyrrolopyridazine, while benzoylacetaldehyde forms a mixture of 2-phenyl and 4-phenylpyrrolopyridazine $65 \mathbf{f}$ and $65 \mathbf{e}$, respectivly. When starting from phenyl-malondialdehyde and 1-aminopyrrole, 3-phenyl-pyrrolopyridazine $\mathbf{6 5 g}$ is obtained. ${ }^{138}$ Around the same period Zupan et al. ${ }^{139}$ synthesized pyrrolopyridazines $\mathbf{6 5 e}$ and $\mathbf{6 5 f}$ in order to study their chemical properties, using the method described by Flitsch and Kramer.

When diketone or acetonylacetate are used as condensation agents, $1(2 H)$-pyrrolopyridazine 66 is obtained. Unsubstituted pyrrolopyridazine 1 was synthesized in $21 \%$ yield from 1 aminopyrrole and 3-ethoxyacroleine diethylacetate (Scheme 34).



64

65a-f

66

65a: $R^{1}=R^{2}=H ; b: R^{1}=R^{2}=M e ; c: R^{1}=R^{2}=P h ; d: R^{1}=M e, R^{2}=P h ; e: R^{1}=H ; R^{2}=P h ; f: R^{1}=P h, R^{2}=H$

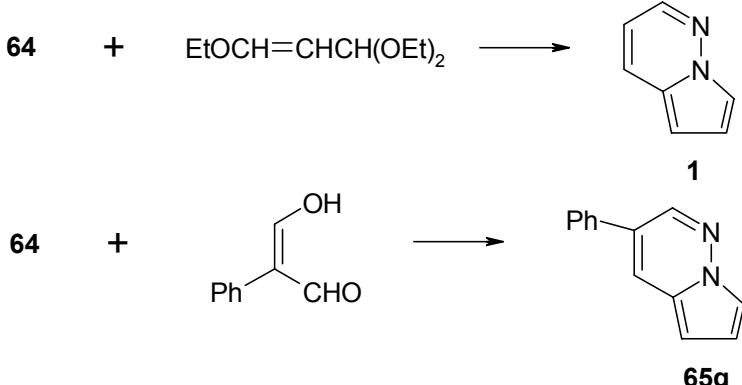

\section{Scheme 34}

Ruxter et al. ${ }^{140}$ synthesized a series of quinolone analogues in order to investigate their antibacterial activity. Among the analogues obtained by the authors is pyrrolopyridazine 68 which was synthesized starting from compound 67 , which in turn was obtained starting from the condensation reaction between diethyl 1-aminopyrrole ethoxymethylenemalonate (Scheme 35). By functional group transformations of compound 68, five new pyrrolopyridazine derivatives were obtained. 




\section{Scheme 35}

Recently, using as raw materials 1-aminopyrrole derivative 69 and 3,3dimethoxypropionitrile, the pyrrolopyridazine derivative 71 was obtained (Scheme 36). ${ }^{141} \mathrm{~A}$ large number of compounds $\mathbf{7 2}$ were synthesized from the chloroderivative $\mathbf{7 1}$ and were tested as MEK inhibitors. MEK is a kinaze which catalyzes the phosphorylation of the tyrosine and treonine residues from other enzymes.<smiles>CCOC(=O)c1cn(N)cc1COCCO</smiles>

69<smiles>CCOC(=O)c1cn2[nH]cc(C#N)c(=O)c2c1C</smiles>

70<smiles>CCOC(=O)c1cn2ncc(C#N)c(Cl)c2c1C</smiles>

71

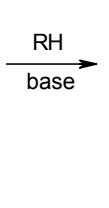<smiles>[R]c1c(C#N)cnn2cc(C(=O)OCC)c(C)c12</smiles>

72

\section{Scheme 36}

\subsection{Syntheses through rearrangement reactions ${ }^{142}$}

To this date, there is only one literature example of such synthesis. By treating 2,3-dihydrodiazepinone $\mathbf{7 3}$ with acid chlorides, the bicyclic compounds $\mathbf{7 4}$ are obtained instead of the expected products. By reacting with DMAD with compounds 74a-c on heating, the cycloadducts 76 are obtained, most likely via a [3+2] cycloaddition between the dipoles $\mathbf{7 5}$ and the triple bond (Scheme 37). ${ }^{142}$ The cycloadducts 76 a-c rearrange in various conditions to pyrrolopyridazines 77a-c, with the structure of compound $77 \mathbf{c}$ confirmed by X-ray analysis. ${ }^{143}$



Scheme 37 


\subsection{Syntheses from Acyclic Compounds}

1.4.1. The condensation of $\mathbf{1 , 4 , 7 - t r i k e t o n e s ~ w i t h ~ h y d r a z i n e ~ h y d r a t e . ~} 1,4,7$-Triketones $\mathbf{7 8}$, by condensation with with hydrazine hydrate, lead in different reaction conditions to 4,5-dihydropyrrolo[1,2-b]pyridazines $\mathbf{7 9}$ or 3,4-dihydro-pyrrolo[1,2-b]pyridazines $\mathbf{8 0}$ (Scheme 38). The aromatization of compounds $\mathbf{8 0}$ to pyrrolo[1,2-b]pyridazines $\mathbf{8 1}$ was performed in toluene at reflux, using chloranil (tetrachlorobenzoquinone) as oxidant. ${ }^{144}$

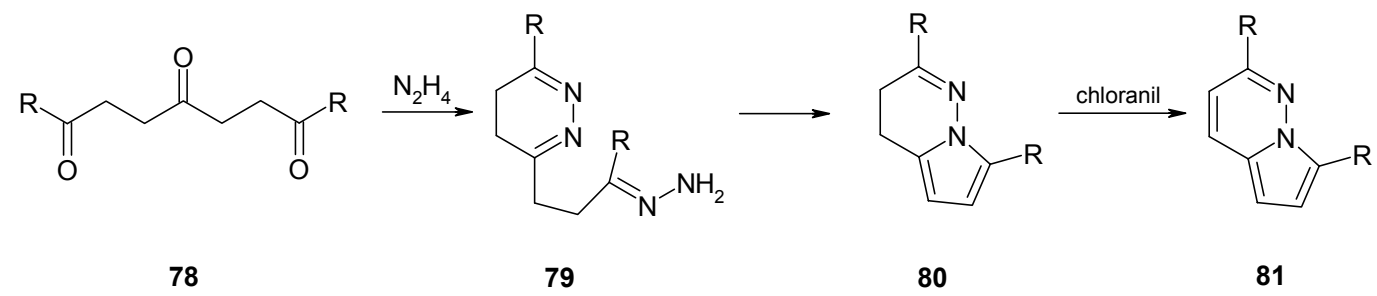

\section{Scheme 38}

1.4.2. The intramolecular $[4+2]$ cycloaddition of conjugated azoalkenes. Gilchrist et al. studied the ability of conjugated azoalkenes to give intramolecular [3+2] cycloaddition reactions, ${ }^{145,146}$ which are rarely encountered for this type of compounds. ${ }^{147,148}$ Treating unsaturated hydrozones $\mathbf{8 2}$ with anhydrous sodium bicarbonate in methylene chloride proved to be an interesting method for the synthesis of hexadropyrrolo[1,2-b]pyridazines 84 (Scheme 39). For the formation of the bicyclic compounds 84 a mechanism was proposed, involving the intramolecular [4+2] cycloaddition of the unsaturated diazene 83. Compounds 82 were obtained via the condensation between $\alpha$-halogenoketone and the hydrazide of 4-pentenoic acid (Scheme 40).

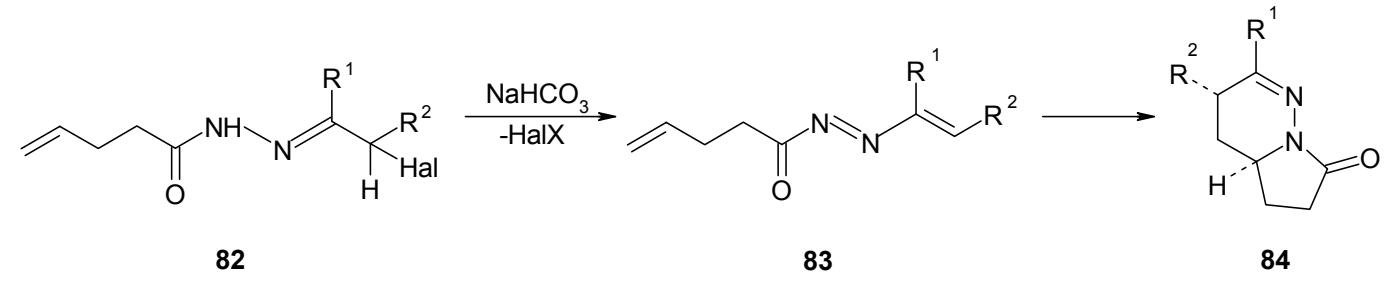

Scheme 39<smiles>[R]C(=O)C([R])[13CH](C)CC</smiles>

\section{Scheme 40}


Tetrahydro-pyrrolopyridaznies $\mathbf{8 4}$ were reduced stereoselectively using an Adams catalyst to the corresponding hexahydropyrrolopyridazines $\mathbf{8 5} .{ }^{146}$ The acetylation of the nitrogen atom with acetic anhydride of compounds $\mathbf{8 5}$, followed by the reacton with sodium in liquid ammonia, leads to the cleavage of the N-N bond and the formation of pyrolidinones $\mathbf{8 6}$ (Scheme 41). ${ }^{146}$



84

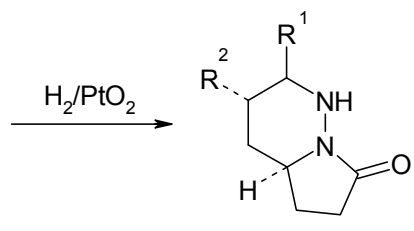

85

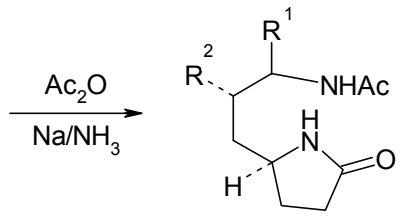

86

\section{Scheme 41}

Similarly, hydrazones derived from 4-pentanoic acid $\mathbf{8 7}$ form tetrahydro-pyrrolopyridazines 89 under the action of sodium bicarbonate. ${ }^{149}$ The mechanism implies the cyclization of azoalchines $\mathbf{8 8}$ which are generated in situ by the dehydrohalogenation of halogeno-hydrazones 87 (Scheme 42).



87



88

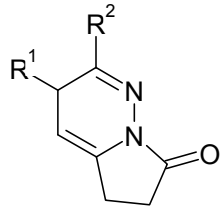

89

\section{Scheme 42}

The [4+2] intramolecular cycloaddition of azoalkenes $\mathbf{9 0}$ leads in good yields under high dilution conditions to hexa- and octahydro-pyrrolopyridazines 91, together with variable amounts of tetrahydropyridazine derivatives $\mathbf{9 2} .{ }^{150}$ The mechanism of formation implies the [4+2] cycloaddition between two molecules of unsaturated diazenes $\mathbf{9 0}$ (Scheme 43).

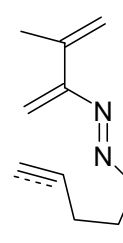

90

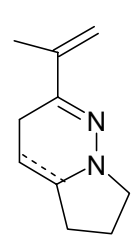

91

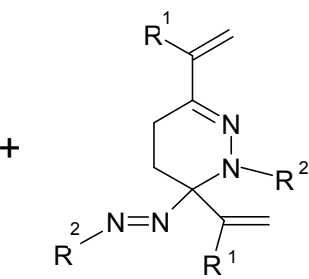

92

\section{Scheme 43}




\subsubsection{From cyanacetic acid hydrazide and 2-phenyl-1,1,3-tricyano-3-bromo-2-propene.} Starting from cyanacetic acid hydrazide and 2-phenyl-1,1,3-tricyano-3-bromo-2-propene in the presence of triethylamine and in DMF medium, Abdelrazek obtained the hexasubstituted pyrrolo[1,2-b]pyridazine 94 (Scheme 44). ${ }^{151,152}$ The author assumes that the nonisolable intermediate $\mathbf{9 3}$, formed by the condensation of the reactants, suffers a double cyclization by the addition of two cyano groups to the active methylene and to the $\mathrm{NH}$ group, respectively. A pyrrolopyridazine derivative with similar structure to compound $\mathbf{9 3}$ was obtained when starting from 2-benzoyl-3-phenylpent-2-ene-1,5-dinitrile and cyanoacetic acid hydrazide. ${ }^{153}$

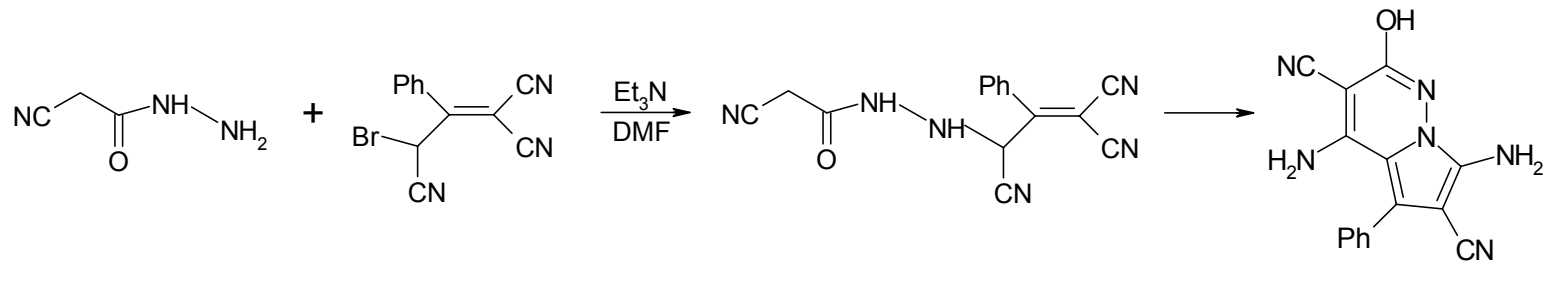

93

94

\section{Scheme 44}

\section{Chemical Properties}

\subsection{Substitution reactions}

As observed by Kuhla and Lombardino in 1977, electrophiles with low or moderate reactivity give monosubstituted pyrrolopyridazine derivatives in the 7 position. Examples are represented by the nitrosation, diazonium coupling, and acylation with trifluoroacetic anhydride (Scheme 45). ${ }^{139}$

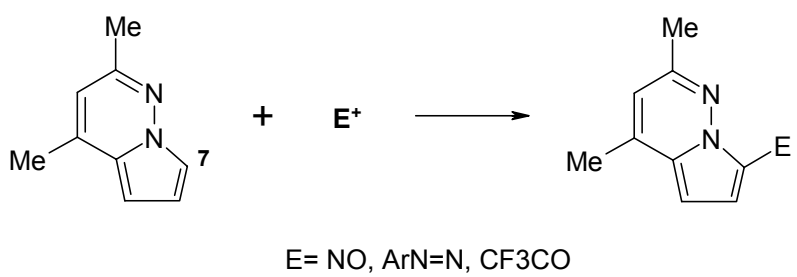

\section{Scheme 45}

Fraser $^{25}$ performed the formylation of pyrrolopyridazines using the Vilsmeier reaction $\left(\mathrm{POCl}_{3}+\mathrm{DMF}\right)$ and obtained 5-formyl pyrrolopyrdazines, as the 7 position was occupied by a phenyl moiety. By the reduction of the 5-formyl-pyrrolopyridazine derivatives with lithium 
aluminohydride in ethyl ether and in the presence of aluminium chloride, two new 5-methylpyrrolopyridazines were synthesized (Scheme 46).

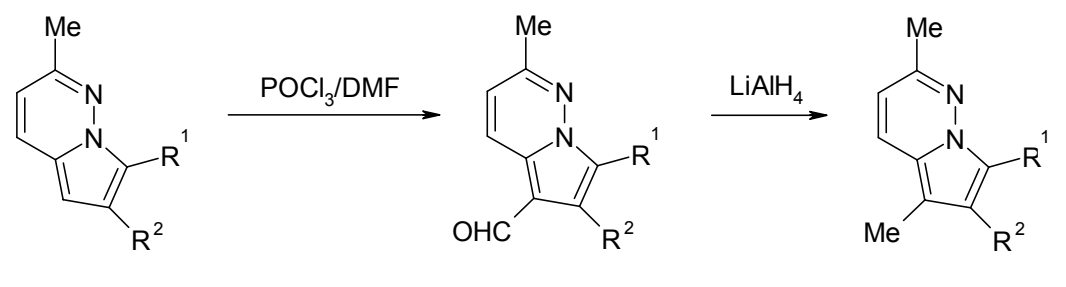

$\mathrm{R}^{1}=\mathrm{R}^{2}=\mathrm{Me} ; \mathrm{R}^{1}=\mathrm{Me}, \mathrm{R}^{2}=\mathrm{Ph}$

\section{Scheme 46}

Strong electrophiles as in the case of bromination and nitration reactions lead to polysubstituted derivatives (Scheme 47). Thus, the bromination reaction of 2,4-dimethyl- and 2methyl-4-phenyl-pyrrolopyridazine leads to the following results: the use of $N$-bromosuccimide leads to 5,7-dibromoderivatives 95a,b; molecular bromine in various solvents (acetic acid, chloroform, carbon tetrachloride) leads to the formation of the tribromo derivatives 96a,b; the tetrabromo derivative 97a was obtained by the bromination of dibromo derivative 95a with bromine in carbon tetrachloride. Flitsch and $\mathrm{Kramer}^{137}$ proposed the structure of 5,6,7-tribromopyrrolopyridazine for the bromination of 2,4-dimethylpyrrolopyridazine $\mathbf{6 5} \mathbf{b}$, but a more rigorous inspection of the NMR spectra indicated a structure corresponding to $96 \mathbf{a} .{ }^{139}$ By treating $65 \mathbf{b}$ with sulfonitric mixture, 5,7-dinitro derivative 98a is obtained. Under the same conditions, the use of pyrrolopyridazine 65c leads to the introduction of a third nitro group in the para position of the benzene ring.

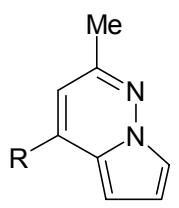

$65 b, c$



95a,b

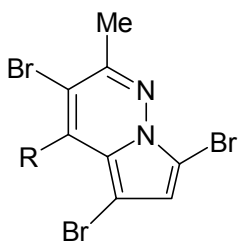

96a,b

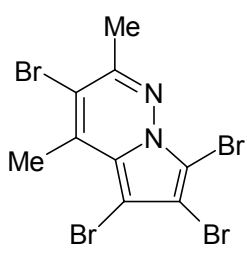

$97 a$

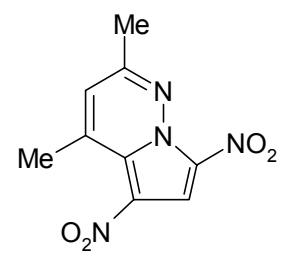

$98 \mathbf{a}$

\section{Scheme 47}

Charge density calculations on the pyrropyridazine ring indicate that electrophilic substitution is strongly favoured for the positions 5 and 7. A good correlation between theoretical computations and the experimental results was observed. ${ }^{139}$

Electrophilic addition to a double or triple activated bond occurs in the 7 position, and if this position is occupied, the reaction occurs at atom $\mathrm{C}-5$. Thus, by the reaction between pyrrolopyridazines and tetracyanoethylene in acetone media in the presence of pyridine, pyrrolopyridazine derivatives $\mathbf{1 0 0}$ are formed (Scheme 48). ${ }^{139}$ The isolation of intermediary 99 
and the fact that it eliminates hydrogen cyanide, forming compound $\mathbf{1 0 0}$, represents proof for the mechanism.<smiles>[R]c1cc([R])c2cccn2n1</smiles>

\section{Scheme 48}

Pyrrolopyridazines unsubstituted at the pyrrole ring form with DMAD compounds 101, by the Michael addition to the triple acetylenic bond (Scheme 49). From the NMR data it was concluded that only the trans isomers were formed in 6 to $69 \%$ yields, with the fumaryl residue found in the 7 position. Together with pyrrolopyridazines 101, compounds $\mathbf{1 0 2}$ are obtained as a result of the intramolecular cyclization of the Michael adducts. This hypothesis is backed up by the fact that by heating in the presence of hydrochloric acid, the transformation $\mathbf{1 0 1} \rightarrow \mathbf{1 0 2}$ is possible. ${ }^{135,137}$ Starting from the Michael adduct 101b, Zupan et al. ${ }^{139}$ obtained the tetracyclic compound 104 (Scheme 49) by a sequence of reactions which includes the alkaline hydrolysis followed by acidification with the formation of anhydride 103, followed by the treating of this with hydrazine hydrate.



$65 a-d$



101a-d

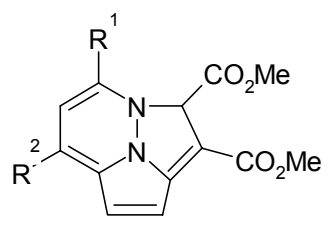

102a-d

a: $R^{1}=R^{2}=H ; b: R^{1}=R^{2}=M e ; c: R^{1}=R^{2}=P h ; d: R^{1}=M e, R^{2}=P h$

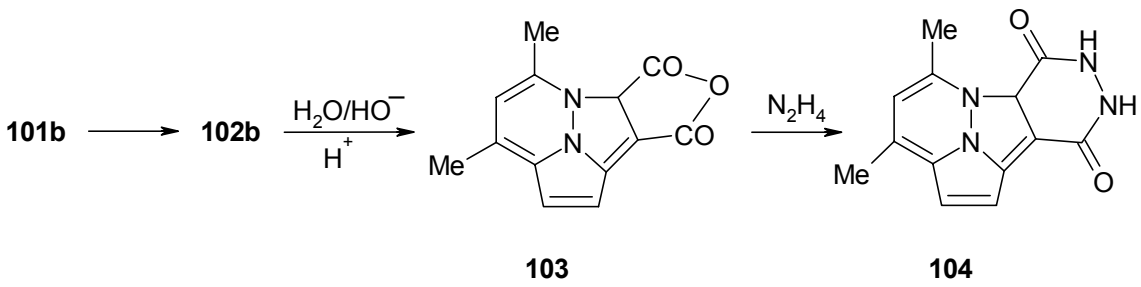

\section{Scheme 49}

Fraser et al. ${ }^{26}$ investigated the reaction between 2,6,7-trimethyl-pyrrolo[1,2-b]pyridazine and DMAD in toluene at room temperature. Because the 7 position in compound $7 \mathbf{b}$ is occupied by a methyl group, the addition takes place in position 5 (Scheme 50). Both $\operatorname{trans}(E)-105$ and $\operatorname{cis}(Z)$ 105 are obtained, in a 2.5/1 ratio, with a total yield of $53 \%$. The two geometric isomers were 
separated by thin layer chromatography (TLC) and their configuration established on the basis of H-NMR data. ${ }^{61-67,154,155}$

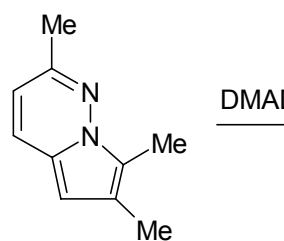

7b

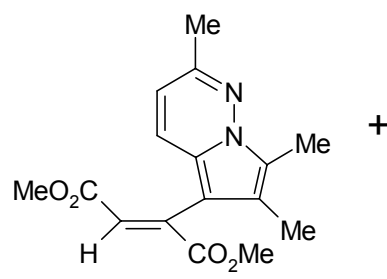

trans-105<smiles>COC(=O)/C=C/c1c(C)c(C)n2nc(C)ccc12</smiles>

cis-105

\section{Scheme 50}

The action of $40 \%$-formaldehyde on 2,6,7-trimethyl-pyrrolo[1,2-b]pyridazine leads to the formation of methylene-bis(5,5'-pyrrolopyridazine) $\mathbf{1 0 6}$ in 98\% yield (Scheme 51). ${ }^{25}$ Protonation with trifluoroacetic acid leads to a mixture containing a species protonated at carbon atoms $\mathrm{C}-7$ and $\mathrm{C}-7^{\prime}(32 \%, \mathbf{1 0 6 a})$ and one at C-2 and C-7' $(32 \%, \mathbf{1 0 6 b})$.


$\mathrm{Me}$

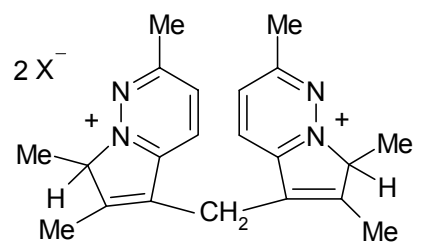

$106 a$



106<smiles>[Y]C1C(C)=C(Cc2c(C)c(C)n3c2ccc(C)[n+]3C)c2ccc(C)n[n+]21</smiles>

$106 b$

\section{Scheme 51}

2-Isocyanosulfonyl methyl benzoate 107 and 2,4-dimethyl-pyrrolo[1,2- $b$ ]pyridazine lead to sulfamide 108 acylated at the nitrogen atom (Scheme 52). The addition of the pyrrolopyridazine residue at the 7 position to the isocyanate moiety takes place in methylene chloride at $-78^{\circ} \mathrm{C} .{ }^{156}$ 


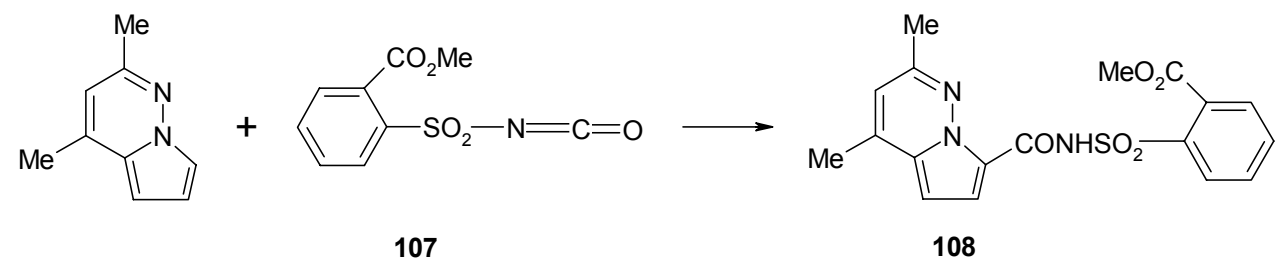

\section{Scheme 52}

6-Aryl-pyrrolopyridazines were heteroarylated with yields in the range of $4-93 \%$ in the 7 position using as arylation agent 3,6-dichloropyridazines in dichloromethane as medium and in the presence of aluminium chloride (Scheme 53). ${ }^{157}$ Heteroarylation with 3-chloro-6methoxypyridazine occurs only in the case of one pyrrolopyridazine derivative with $20 \%$ yield. The reaction represents a new synthetic method for the obtaining of 6,7-disubstituted pyrrolopyridazines with 110 structure. Aiming at obtaining new pyrrolopyridazine derivatives with possible biological applications, the compound with the aryl group 4-ethylphenyl was hydrolized to pyridazinone 111. This was subsequently transformed into ester 112, which in turn was hydrolized to acid 113 (Scheme 53). The synthesis of the intermediate pyrrolopyridazines 109 was performed using the Chichibabin reaction.



109
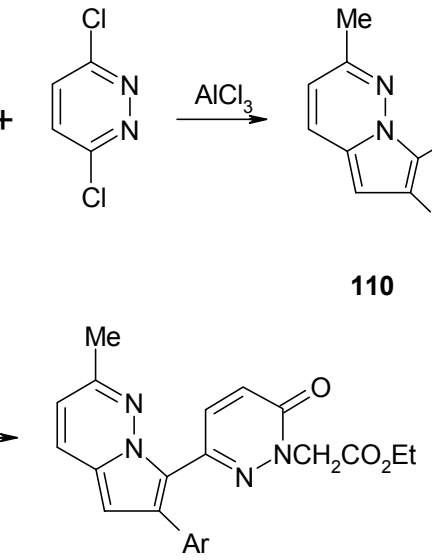

112



110

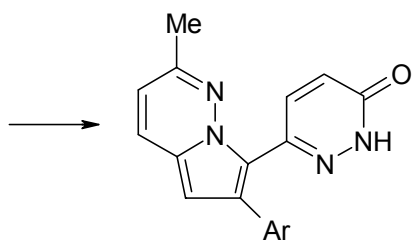

111

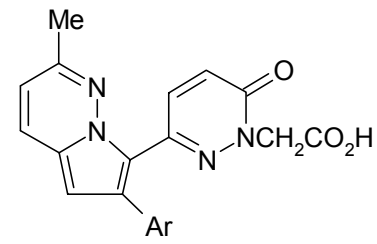

113

\section{Scheme 53}

\subsection{Protonation and deuteration ${ }^{24,25,137}$}

Usually the protonation of a $\mathrm{N}$-aromatic heterocycle occurs at the nitrogen atom, but protonation at a ring carbon atom is also possible. From the studies performed on indolizine and its derivatives, it was shown that protonation occurs at position 3 or 1 . As can be observed (Scheme 54), protonation of the carbon atom leads to a preservation of aromaticity in the pyridine ring and the loss of the weaker aromaticity of the pyrrole ring. It was concluded that the protonation of the nitrogen atom requires more energy than protonation of the carbon atom. 


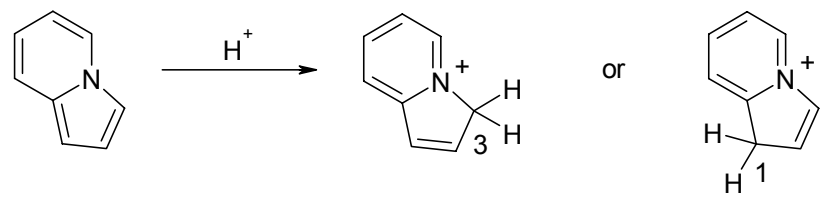

\section{Scheme 54}

Fraser $^{24,25}$ studied the protonation of the seven isomer azaindolizines (Scheme 55).

\section{Scheme 55}

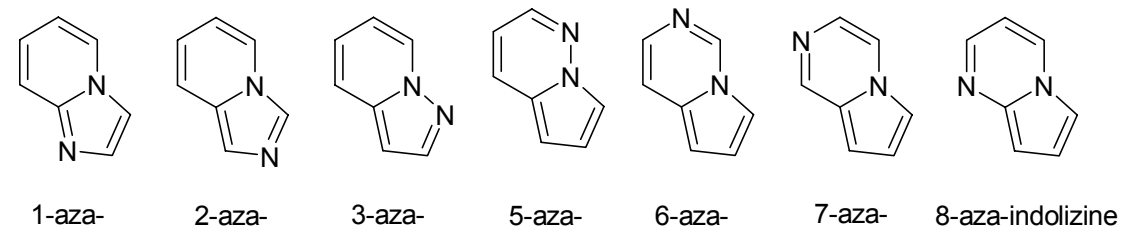

Azaindolizines containing a nitrogen atom in the five-membered ring (imidazo[2,3a]pyridine, imidazo[3,4-a]pyridine and pyrazolo[2,3-a]pyridine) are protonated at this nitrogen atom. The position of protonation was established on the basis of UV-Vis spectroscopy and HNMR spectra. From the second group of azaindolizines having both nitrogen atoms in the six membered ring (pyrrolo[1,2-b]pyridazine, pyrrolo[1,2-c]pyrimidine, pyrrolo[1,2-a]pyrazine and pyrrolo[1,2-a]pyrimidine), 6-aza and 7-azaindolizines are protonated at the formally $s p^{2}$ hybridized nitrogen atom.

The protonation of pyrrolo[1,2-b]pyridazines or 5-azaindolizines depends on the nature, position and number of substituents of the pyrrole ring, as illustrated in Scheme 56. In the case of pyrrolo[1,2-b]pyridazine derivatives with the 7 position unsubstituted are protonated with trifluoroacetic acid there. As proof for the protonation positions, the deuteration experiment with deuterated trifluoroacetic acid results with the substitution of protons 5 and 7 with deuterium. 


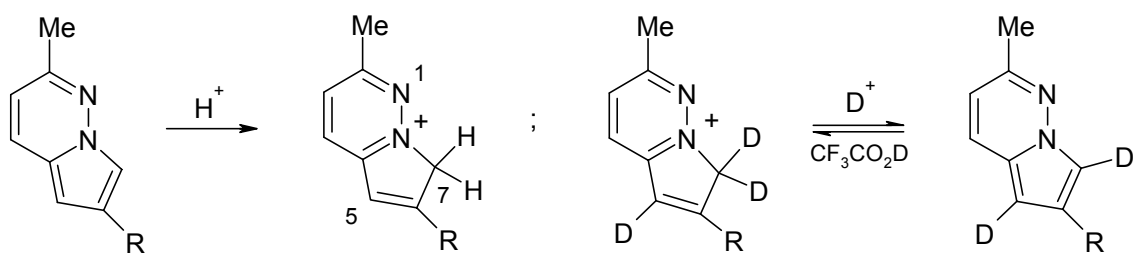

$7 a, 7 c$

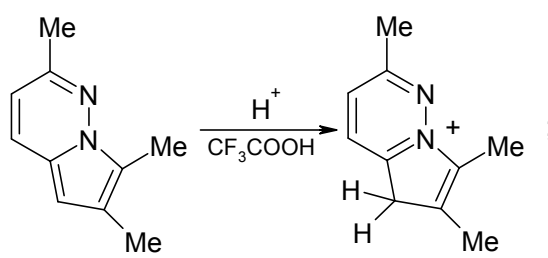

$7 \mathrm{~b}$

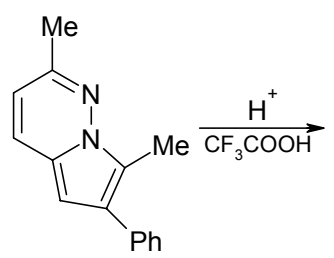

$7 d$

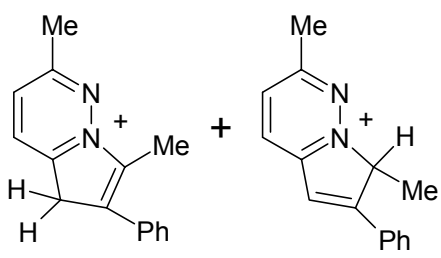

80
20


\section{Scheme 56}

H-NMR data show that protonation of 6-phenyl-5-methyl-pyrrolopyridazine, in the same conditions, leads to a mixture of two species, one protonated at C-7 (80\%) and one at C-5 (20\%). The different protonation of compounds $7 \mathbf{d}$ (protonation at C-5 and C-7) and $7 \mathbf{b}$ (protonation at C-5) can be explained by the steric and electronic effects of the methyl and phenyl groups. In the case when the three hydrogen atoms from the pyrrole ring are substituted by methyl and phenyl (position 6) groups, protonation by trifluoroacetic acid takes place at atom C-7. By using a strongly acidic medium (perchloric acid in ethyl acetate), the reaction is kinetically controlled and nitrogen atom N-1 is protonated. Flitsch and $\mathrm{Kramer}^{138}$ established independently from Fraser that pyrrole-unsubstituted pyrrolopyridazine protonation takes place with trifluoroacetic acid at C-7 in 10\%. Deuterium substitution ( $\mathrm{CF}_{3} \mathrm{COOD}$ ) implies the atoms $\mathrm{H}-5$ and $\mathrm{H}-7$.

As a result of the deuteration studies on pyrrolopyridazines the following conclusions can be drawn: protonation usually occurs at C-7, and when this position is occupied, at C-5; the process is kinetically or thermodynamically controlled, this being determined by the strength of the protonation agent; the results are not in agreement with theoretical computations, which indicate the highest electron density at atom N-1.

\subsection{Pyrrolopyridazine hydrogenation ${ }^{51}$}

The hydrogenation of pyrrolopyridazines was recently reported in the literature. ${ }^{51}$ By treating with zinc in acetic acid at reflux, pyrrolopyridazines $\mathbf{3 2} \mathbf{a}$ and $\mathbf{3 5} \mathbf{b}, \mathbf{c}$ are hydrogenated selectively 
in positions 3 and 4 (Scheme 57). The structure of 3,4-dihydropyrrolopyridazines 114a-c was established on the basis of NMR data and X-ray analysis for compound $\mathbf{1 1 4 b}$. The hydrogenation of dihydro-pyrrolopyridazines to tetrahydro-pyrrolopyridazines and of hexahydropyrrolopyridazines 84 to octahydro-pyrrolopyridazines 85 was mentioned above. ${ }^{146}$

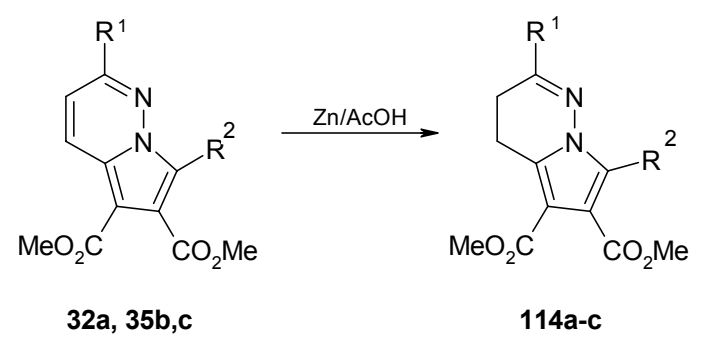

114a: R1=R2=Me; 114b: R1=Ph, R2=H; 114c: R1=4-MeC6H4 R2=H

\section{Scheme 57}

\subsection{Transformation of the functional groups}

Numerous papers describe transformations of the functional groups and many examples were presented above. The fact that pyrrole acids decarboxylate easily and with good yields was utilized by many authors. ${ }^{2,4,79,158}$

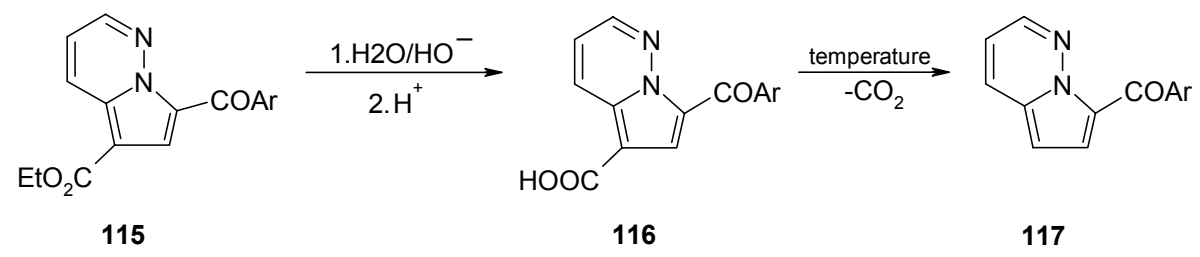

\section{Scheme 58}

A good example is the synthesis of 7-aroyl-pyrrolopyridazines 117 by the hydrolysis of cycloadducts 115 to acids 116, followed by their decarboxylation by simple heating above their melting point (Scheme 58). ${ }^{79}$

Other examples of chemical transformations of the functional groups grafted on the pyrrolopyridazine scaffold such as transesterification, ${ }^{4}$ cyano group hydrolysis to ester, ${ }^{4}$ or the acylation of an amino group ${ }^{36}$ are presented in Scheme 59. 



\section{Scheme 59}

\section{Physico-chemical and Biological Properties}

UV-Vis spectra of pyrrolopyridazines are presented in many papers, usually together with fluorescence studies..$^{3-5,24,135}$ Although the high fluorescence of pyrrolopyridazines was known since the 1970's, ${ }^{24,135}$ the first quantitative study of their fluorescent properties and how substituents alter them was performed by Wudl et al. ${ }^{3}$ in 1999. After this, numerous articles treated the optical properties and especially the fluorescence of such compounds in detail. 4,5,102,159,160 For example, Wudl et al. ${ }^{159}$ synthesized and polymerized a series of monomers containing grafted pyrrolopyridazinic residues (Scheme 60). Fluorescence studies of these polymers showed a long quench time, strong solid state luminiscence and a high quantum yield. The resulting polymers can be made into films or fibers, which makes them suitable for use in optoelectronic devices.

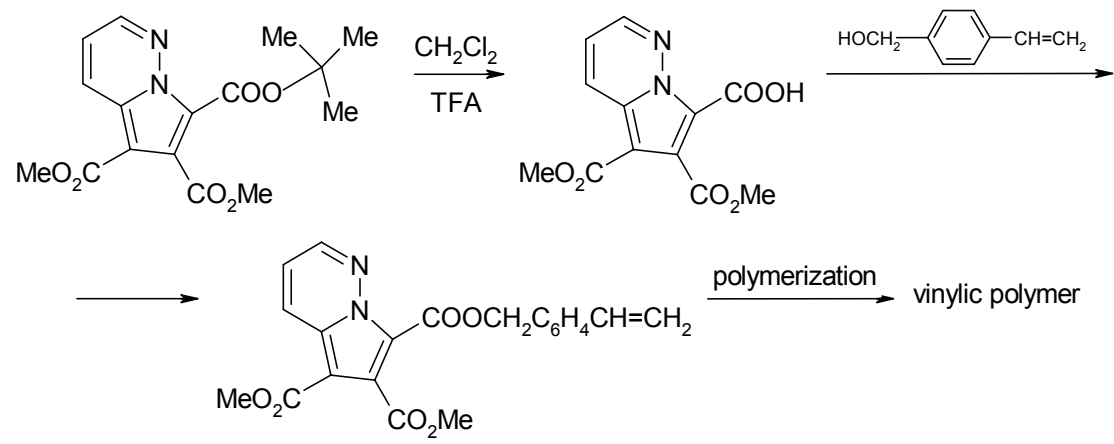

\section{Scheme 60}


Mass spectrometry has been used only for determining the molecular mass, as no studies on the fragmentation mechanisms of pyrrolopyridazine derivatives have been performed to this date. $^{27,71,161}$ IR and NMR spectroscopies were used for structural assignment. NMR data is readily available in papers treating the synthesis and chemical transformations of pyrrolo[1,2b]pyridazines.

The phenomenon of photochromism of spiro-indolizines and spiro-pyrrolopyridazines was investigated by Durr et al. ${ }^{119-126}$

X-ray analysis of pyrrolopyridazines and their dihydro- and tetrahydro- derivatives was used by several research groups for structural determination and SAR analyses. ${ }^{4,5,51,88,143,158,162}$

For further use in SAR correlations, as long ago as 1968 computational methods were used, on the basis of which the electron densities and ionization potentials were calculated. ${ }^{163-166}$ Such computations indicated high electron densities in positions 7 and 5, which is in good agreement with electrophilic substitution experiments. While investigating the optical properties of pyrrolopyridazines, Wudl et al. ${ }^{4}$ explained their unexpected blue and powerful red shift using DFT computations at the B3LYP level of theory. ${ }^{167-170}$ Furthermore, DFT and TD-DFT computations were used for obtaining detailed information on the structure of pyrrolopyridazines in the aim of explaining the differences observed in their absorbtion spectra. ${ }^{160}$

Pyrrolo[1,2- $b$ ]pyridazine derivatives show various biological activities such as antimicrobial activity, enzyme inhibition, herbicides, etc. Research on the biological action of pyrrolopyridazines intensified four decades after their first synthesis in $1956,{ }^{2}$ with many papers and patents on this subject are available. ${ }^{32-34,100,101,103,140,141,156,171-176}$

\section{References}

1. Kuhla, D. E.; Lombardino, J. G. Adv. Heterocycl. Chem. 1977, 21, pp 50-65.

2. Letsinger, R. L.; Lasco, R. J. Org. Chem., 1956, 21, 764.

3. Cheng, Y.; Ma, B.; Wudl, F. J. Mater. Chem. 1999, 9, 2183.

4. Mitsumori, T.; Bendikov, M.; Sedó, J.; Wudl, F. Chem. Mater., 2003, 15, 3759.

5. Swamy, K. M. K.; Park, M. S.; Han, S. J.; Kim, S. K.; Kim, J. H.; Lee, C.; Bang, H.; Kim, Y.; Kim, S.J.; Yoon, J. Tetrahedron 2005, 61, 10227.

6. Acheson, R. M.; Elmore, N. F. Adv. Heterocycl. Chem., 1978, 23, pp. 263-482.

7. Acheson, R. M.; Procter, G.; Critchley, R. Chem. Commun. 1976, 962.

8. Acheson, R. M.; Procter, G. J. Chem. Soc. Trans 1 1977, 1924.

9. Tighineanu, E.; Răileanu D.; Simonov, Yu.; Bouroş, P. Tetrahedron, 1996, 52, 12475.

10. Yavari, I.; Maghsoodlou, M. T.; Pourmossavi, A. J. Chem. Res. (S), 1997, 212.

11. Wahe, H.; Mbafor, J. T.; Nkengfack, A. E.; Fomum, Z. T.; Cherkasov, R. A.; Sterner, O.; Doepp, D. ARKIVOC 2003, (xv), 107-114.

12. Katritzky, A. R.; Rogers, J. W.; Witek, R. M.; Nair, S. K. ARKIVOC 2004, (xv), 52-60. 
13. Cavdar, H.; Saracoglu, N. J. Org. Chem. 2006, 71, 7793.

14. Sahoo, M. K. Synlett 2007, 2142.

15. Dumitraşcu, F.; Caira, M. R.; Barbu, L.; Miu, B.; Drăghici, B. Anal. Sci. X 2008, 24 , x27.

16. Maghsoodlou, M. T.; Pour, B. T.; Marandi, G.; Akbarzadeh, N. ARKIVOC 2008, (ii), 153.

17. Arango, E. P.; Iglesias, M. J.; Alvarez-Manzaneda, R.; Ortiz, F. L. ARKIVOC 2007, (iv), 102.

18. Diels, O.; Meyer, R. Justus Liebig Ann. Chem. 1943, 513, 129.

19. Acheson, R. M.; Foxton, M. W. J. Chem. Soc. (C) 1966, 2218.

20. Chichibabin, A. E. Ber. 1927, B60, 1607.

21. Uchida, T.; Matsumoto, K. Synthesis 1976, 209.

22. Swinbourne, F. J.; Hunt, J.; Klinkert, K. Adv. Heterocycl. Chem. 1978, 23, 103.

23. Flitsch, W. Comprehensive Heterocyclic Chemistry, Katritzky, A. R.; Rees, C. W., Ed., Pergamon: Oxford, 1984, Vol. 4, p 476.

24. Fraser, M. J. Org. Chem. 1971, 36, 3087.

25. Fraser, M. J. Org. Chem. 1972, 37, 3027.

26. McHattie, D.; Buchan, R.; Fraser, M.; Kong Too Lin, P. V. S. Heterocycles 1992, 34, 175971.

27. Lown, J. W.; Matsumoto, K. Can. J. Chem. 1971, 49, 1165.

28. Lown, J. W.; Matsumoto, K. Can. J. Chem. 1971, 49, 3119.

29. Wadsworth, D. H.; Bender, S. L.; Smith, D. L.; Luss, H. R. Tetrahedron Lett. 1981, 22, 3569.

30. Wadsworth, D. H.; Bender, S. L.; Smith, D. L.; Luss, H. R.; Weidner, C. H. J. Org. Chem. 1981, 22, 3569.

31. Weidner, C. H.; Michaels, F. M.; Beltman, D. J.; Montgomery, C. J.; Wadsworth, D. H.; Briggs, B. T.; Picone, M. L. J. Org. Chem. 1991, 56, 5594.

32. Østby, O. B.; Gundersen, L.-L.; Rise, F.; Antonsen, Ø.; Fosnes, K.; Larsen, V.; Bast, A.; Custers, I.; Haenen, G. R. M. M. Arch. Pharm. Pharm. Med. Chem. 2001, 334, 21.

33. Nasir, A. I.; Gundersen, L.-L.; Rise, F.; Antonsen, Ø.; Kristensen, T.; Langhelle, B.; Bast, A.; Custers, I.; Haenen, G. R. M. M.; Wikström, H. Bioorg. Med. Chem. Lett. 1998, 8, 1829.

34. Østby, O. B.; Dalhus, B.; Gundersen, L.-L.; Rise, F.; Bast, A.; Haenen, G. R. M. M. Eur. J. Org. Chem. 2000, 9, 3763.

35. Siriwardana, A. I.; Nakamura, I.; Yamamoto, Y. J. Org. Chem. 2004, 69, 3202.

36. Satoh, K.; Miyasaka, T.; Arakawa, K. Yakugaku Zasshi 1977, 97, 422.

37. Ohsawa, A.; Abe, Y.; Igeta, H. Bull. Chem. Soc. Jpn. 1980, 53, 3273.

38. Ohsawa, A.; Abe, Y.; Igeta, H. Chem. Pharm. Bull. 1980, $28,3488$.

39. Veeraraghavan, S.; Bhattacharjee, D.; Popp, F. D. J. Heterocycl. Chem. 1981, 18, 443.

40. McEwen, W. E.; Cobb, R. L.; Chem. Rev. 1955, 55, 511.

41. Popp, F. D. Adv. Heterocycl. Chem. 1968, 9, 1.; Popp, F. D. Adv. Heterocycl. Chem. 1979, 24, 187.

42. Popp, F. D. Heterocycles 1980, 14, 1033. 
43. Sieck, O.; Schaller, S.; Grimme, S.; Liebscher, J. Synlett 2003, 337.

44. Ichikawa, E.; Suzuki, M.; Yabu, K.; Albert, M.; Kanai, M.; Shibasaki, M. J. Am. Chem. Soc. 2004, 126, 11808-11809.

45. Brozda, D.; Hoffman, K.; Rozwadowska, M. D. Heterocycles 2006, 67, 119.

46. Gibson, H. W.; Berg, M. A. G.; Dickson, J. C.; Lecavalier, P. R.; Wang, H.; Merola, J. S. J. Org. Chem. 2007, 72, 5759.

47. Reimann, E.; Renz, M. Monatsh. Chem. 2007, 138, 211.

48. Masanori, N.; Sumiko, M.; Hiroshi, T.; Katsuhide, M.; Takao, Y. Chem. Pharm. Bull. 1975, 23, 30561 .

49. Nielsen, P. E.; Haaima, G.; Eldrup, A. B. US Patent 6632919.

50. Bascop, S.-I.; Laronze, J.-Y.; Sapi, J. Synthesis 2002, 1689.

51. Dumitraşcu, F.; Caira, M. R.; Drăghici, B.; Căproiu, M. T.; Dumitrescu, D. G. Synlett 2008, 813.

52. Palmer, D. C. In Oxazoles: Synthesis, Reactions and Spectroscopy, Part A; Ed. John Wiley \& Sons: New Jersey, 2003, pp 473-576.

53. Gribble, G. W. In Synthetic Applications of Dipolar Cycloaddition Chemistry towards Heterocycles and Natural Product; Padwa, A.; Pearson, W. H., Ed. John Wiley \& Sons, New York, 2002, pp 681-754.

54. Potts, K. T. In 1,3-Dipolar Cycloaddition Chemistry; Padwa, A.; Ed. Wiley New York, 1984, Vol. 2, pp. 1-81.

55. Ollis, W. D.; Stanforth, S. P.; Ramsden, C. A. Tetrahedron 1985, 41, 2239.

56. Ramsden, C. A.; Newton, C. G. Tetrahedron 1982, 38, 2965.

57. Ramsden, C. A. In Comprehensive Organic Chemistry, 1979, Vol. 4, p 1171-1228, Barton, D.H.R; Ollis, W. D. Ed., Academic Press: New York, 1979.

58. Ollis, W. D.; Ramsden, C. A. Adv. Heterocycl. Chem. 1976, 19, pp 1.

59. Huisgen, R.; Gotthardt, H.; Bayer, H. O. Angew. Chem. Int. Ed. 1964, 3, 135.

60. Huisgen, R.; Gotthardt, H.; Bayer, H. O. Chem. Ber. 1970, 103, 2356.

61. Pleininger, H.; Wild, D. Chem. Ber. 1966, 99, 3070.

62. Fried, F.; Taylor, J. B.; Westwood, R. Chem. Commun. 1971, 226.

63. Tighineanu, E.; Răileanu, D. Rev. Roum. Chim. 1992, 37, 1307.

64. Darehkordi, A.; Saidi, K.; Islami, R. I. ARKIVOC 2007, (i), 180.

65. Kamila, S.; Koh, B.; Zhang, H.; Biehl, E. R. ARKIVOC 2006, (ii), 1.

66. Barillier, D.; Strobel, M. P.; Morin, L.; Paquer, D. Tetrahedron 1983, 39, 767.

67. Jones, R. A.; Sepulveda Arques, J. Tetrahedron 1981, 37, 1597.

68. Farnum, D. G.; Alaimo, R. J.; Dunston, J. J. Org. Chem. 1967, 32, 1130.

69. Masaki, Y.; Otsuka, H.; Nakayama, Y.; Hioki, M. Chem. Pharm. Bull. 1973, 21, 2780.

70. Kobayashi, Y.; Kutsuma, T.; Morinaga, K. Chem. Pharm. Bull. 1971, 19, 2106.

71. Sasaki, T.; Kanematsu, K.; Yukimoto, Y.; Ochiai, S. J. Org. Chem. 1971, 36, 813.

72. Ikemi, Y.; Matsumoto, K.; Uchida, T. Heterocycles 1983, 20, 1009. 
73. Petrovanu, M.; Mai Van, T. Bul. Inst. Politeh. Iasi 1975, Tomul XXI (XXV), fasc.3-4, Sect. 2, 53-61; Chem. Abstr. 1976, 85, 63614h.

74. Petrovanu, M.; Mai Van, T.; Barboiu, V. Rev. Roum. Chim. 1976, 21, 717.

75. Mangalagiu, I.; Caprosu, M.; Druta, I. Petrovanu, M.; An. Stiint. Univ. "Al. I. Cuza" Iassi, Chim. 1994, s2c, 80.

76. Caprosu, M.; Mangalagiu, I.; Olariu, I.; Roman, M. An. Stiint. Univ. "Al. I. Cuza" Iasi, Chim. 1999, 7(2), 321-326; Chem. Abstr. 133, 207493.

77. Mangalagiu, I. I.; Caprosu, M. C.; Mangalagiu, G. C.; Zbancioc, G. N.; Petrovanu, M. Ghe. ARKIVOC 2002, (ii), 73.

78. Georgescu, E.; Georgescu, F.; Roibu, C.; Iuhas, P.; Drăghici, C.; Căproiu, M. T. Rev. Roum. Chim. 2002, 47, 885 .

79. Dumitraşcu, F.; Drăghici, C.; Albulescu, A.; Dumitrescu, D. Rev. Chim. (Bucharest) 2006, $57,866$.

80. Georgescu, E.; Georgescu, F.; Iuhas, P.; Drăghici, C.; Dănila, M.; Filip, P. ARKIVOC 2007, $(x), 381$.

81. Petrovanu, M.; Druță, I.; Mai Van, T. Rev. Roum. Chim. 1978, 23, 781.

82. Caprosu, M.; Ungureanu, M.; Druță, I.; Petrovanu, M. Bul. Inst. Politehnic Iasi 1979, Tomul XXV, fasc.1-2, Sect. 2, 79-84. Chem. Abstr. 1980, 92, 198338y.

83. Tsuge, O.; Kanemasa, S.; Takenaka, S. Bull. Chem. Soc. Jpn. 1985, 58, 3320.

84. Mangalagiu, I.; Petrovanu, M. Acta Chem. Scand. 1997, 51, 927.

85. Caprosu, M.; Mangalagiu, I.; Sirbu, D.; Olariu, I.; Petrovanu, M. An. Stiint. Univ. "Al. I. Cuza" Iasi, Chim. 1997, 5, 95-102; Chem. Abstr. 2000, 132, 207816k.

86. Caproşu, M.; Olariu, I.; Mangalagiu, I.; Constantinescu, M.; Petrovanu, M. Eur. J. Org. Chem., 1999, 3501.

87. Roman, M.; Caprosu, M.; Mangalagiu, I.; Costantinescu, M.; Petrovanu, M. An. Stiint. Univ. "Al. I. Cuza" Iasi, Chim. 2000, 8(1), 145.

88. Dumitraşcu, F.; Caira, M. R.; Drăghici, C.; Caproiu, M.T.; Miu, B.; Barbu, L. ARKIVOC 2008, (xii), 51.

89. Zhang, X.-C.; Huang, W.-Y. J. Fluorine Chem. 1998, 87, 57.

90. Zhang, X.-C.; Huang, W.-Y. Synthesis 1999, 51.

91. Khlebnikov, A. F.; Kostik, E. I.; Kostikov, R. R. Synthesis 1993, 568.

92. Khlebnikov, A. F.; Kostik, E. I.; Kopf, J.; Aleksandrov, E. V.; Kostikov, R. R. Russ. J. Org. Chem. 1998, 34, 712.

93. Petrovanu, M.; Stefănescu, E.; Druță, I. Rev. Roum. Chim. 1971, 16, 1107.

94. Petrovanu, M.; Stefănescu, E.; Druță, I. An. Stiint. Univ. "Al. I. Cuza" Iasi, Chimie 1973, Sect 1c 19, 175-181; Chem. Abstr. 1974, 80:108471.

95. Zugravescu, I.; Petrovanu, M. N-Ylid Chemistry, McGraw-Hill, 1976, p 239.

96. Mangalagiu, I.; Druță, I.; Constantinescu, M.; Humelnicu, I.; Petrovanu, M. Tetrahedron, 1996, 52, 8853 . 
97. Matsumoto, K.; Uchida, T.; Ikemi, Y.; Tanaka, T.; Asahi, M.; Kato, T.; Konishi, H. Bull. Chem. Soc. Jpn. 1987, 60, 3645.

98. Butler, R. N.; Coyne, A. G.; Cunningham, W. J.; Burke, L. A. J. Chem. Soc. Perkin Trans. 2, 2002, 1807.

99. Butler, R. N.; Cunningham, W. J.; Coyne, A. G.; Burke, L. A. J. Am. Chem. Soc. 2004, 126, 11923.

100.Ungureanu, M.; Mangalagiu, I.; Grosu, G.; Petrovanu, M. Ann. Pharm. Fr. 1997, 55, 69.

101.Caprosu, M. D.; Butnariu, R. M.; Mangalagiu, I. I. Heterocycles 2005, 65, 1871.

102.Zbancioc, G. N.; Mangalagiu, I. Synlett 2006, 804.

103.Butnariu, R. M.; Caprosu, M. D.; Bejan, V.; Ungureanu, M.; Poiata, A.; Tuchilus, C.; Florescu, M.; Mangalagiu, I. I. J. Heterocycl. Chem. 2007, 44, 1.

104.Dumitraşcu, F.; Mitan, C. I.; Drăghici, C.; Căproiu, M. T.; Răileanu, D. Tetrahedron Lett. 2001, 8379.

105.Linn, W. J.; Webster, O. W.; Benson, R. E. J. Am. Chem. Soc. 1965, 57, 3651.

106.Dumitraşcu, F.; Drăghici, C.; Miu, B.; Căproiu, M. T.; Barbu, L.; Dumitrescu, D.G. Rev. Roum. Chim. 2008, 53, 261.

107.Dumitraşcu, F.; Drăghici, C.; Miu, B.; Dumitrescu, D.G.; Popa, M.M. Rev. Roum. Chim. 2008, 53, 509.

108.Wei, X.; Hu, Y.; Li, T.; Hu, H. J. Chem. Soc., Perkin Trans. I 1993, 2487.

109.Zhou, J.; Hu, Y.; Hu, H. J. Chem. Res.(S), 1999, 136.

110.Wang, B.; Zhang, X.; Li, J.; Jiang, X.; Hu, Y.; Hu, H. J. Chem. Soc., Perkin Trans. I 1999, 1571 .

111.Zhou, J.; Hu, Y.; Hu, H. J. Heterocycl. Chem. 2000, 37, 1165.

112.Wang, B.; Hu, J.; Zhang, X.; Hu, Y.; Hu, H. J. Heterocycl. Chem. 2000, 37, 1533.

113.Georgescu, E.; Georgescu, F.; Dănila, M.; Filip, P.; Drăghici, C.; Căproiu, M. T. ARKIVOC 2002, (ii), 30 .

114.Dumitraşcu, F.; Drăghici, C.; Căproiu, M.T.; Dumitrescu, D.; Bădoiu, A. Rev. Roum. Chim. 2006, $51,643$.

115.Dumitraşcu, F.; Caira, M. R.; Vasilescu, M.; Barbu, L.; Drăghici, C.; Dumitrescu, D.G. ARKIVOC, 2007, (xvi), 101.

116.Cookson, R.C.; Isaacs, N. S. Tetrahedron 1963, 19, 1237.

117.Zirngibl, L.; Kunz, G.; Pretsch, E. Tetrahedron Lett. 1971, 4189.

118. Hocking, M. B. J. Heterocycl. Chem. 1977, 14, 829.

119.Hauck, G.; Durr, H. Angew. Chem. 1979, 91, 1010; Angew. Chem. Int. Ed. Engl. 1979, 18, 945.

120.Durr, H.; Gross, H.; Zils, K.-D. D.O.S Pat. 32202671, 1981.

121.Durr, H.; Gross, H.; Zils, K.-D.; Hauck, G.; Klauck, G.; Hermann, H. Chem. Ber. 1983, 116, 3915.

122.Durr, H.; Bach, V. Pat. DE3710889, 1988.

123.Durr, H.; Hauck, G. Pat. DE 29061193C2, 1991. 
124.Durr, H. Chimia 1994, 11, 514.

125.Durr, H. Angew. Chem. 1989, 101, 427.

126.Durr, H. In Photochromism: Molecules and Systems, Durr, H.; Bouas-Laurent, H., Eds., Elsevier: Amsterdam, 1990, p 210.

127.Andreis, C.; Durr, H.; Wintgens, V.; Valat, P.; Kosssanyi, J. Chem. Eur. J. 1997, 3, 509.

128.Bleisinger, H.; Scheidhauer, P.; Durr, H.; Wintgens, V.; Valat, P.; Kossanyi, J. J. Org. Chem. 1998, 63, 990.

129.Rustemeyer, F.; Pozzo, J.-L.; Bouas-Laurent, H.; Dürr, H. J. Mat. Chem. 1999, 9, 22452250.

130.Fromm, R; Ahmed, S. A; Hartmann, T; Huch, V; Abdel-Wahab, A. A; Durr, H. Eur. J. Org. Chem. 2001, 21, 4077-4080.

131.Bouas-Laurent, H.; Dürr, H. Pure Appl. Chem. 2001, 639.

132.Crano, J. C.; Guglielmetti, R. J. Organic Photochromic and Thermochromic Compounds, Dürr, H. Vol. 1. Chapter 6, pp. 223-266; Ed. Kluwer Academic 2002.

133. Ahmed, S. A. J. Phys. Org. Chem. 2006, 19, 402.

134.Ahmed, S. A. J. Phys. Org. Chem. 2007, 20, 574.

135.Flitsch, W.; Kramer, U. Tetrahedron Lett. 1968, 1479.

136.Flitsch, W.; Kramer, U.; Zimmermann, H. Chem. Ber. 1969, 102, 3268.

137.Flitsch, W.; Kramer, U. Liebigs Ann. Chem. 1970, 735, 35.

138.Coppola, G. M.; Hardtmann, G. E.; Huegi, B. S. J. Heterocyclic Chem. 1974, 11, 51.

139.Zupan, M.; Stanovnik, B.; Tisler, M. J. Heterocyclic Chem. 1971, 8, 1.

140.Ruxter, J.M.; Lachoux, C.; Ousset, J.B.; Torregrosa, J.L.; Mattioda, G. J. Heterocyclic Chem. 1994, 31, 409.

141.Chen, Z.; Kim, S.-H.; Barbosa, S.A.; Huynh, T.; Tortolani, D.R.; Leavitt, K. J.; Wei, D.D.; Manne, V.; Ricca, C. S.; Gullo-Brown, J.; Poss, M. A.; Vaccaro, W.; Salvati, M. E. Bioorg. Med. Chem. Lett. 2006, 16, 628.

142.Rothenberger, O. S.; Moore, J. A. J. Org. Chem. 1972, 37, 3774.

143. Moore, J. A.; Gearhart, R. C.; Rothenberger, O. S.; Thortenson, P. C.; Wood, R. H. J. Org. Chem. 1972, 37, 2796.

144. Stetter, H.; Landscheidt, A. J Heterocyclic Chem. 1979, 16, 839.

145. Gilchrist, T. L.; Richards, P. Synthesis 1983, 153.

146. Gilchrist, T. L.; Hughes, D.; Wasson, R. Tetrahedron Lett. 1987, 28, 1573.

147.Sommer, S. Angew. Chem. 1979, 91, 756; Angew. Chem. Int. Ed. Engl. 1979, 18, 695.

148.Schultz, A. G.; Hagmann, W. K.; Shen, M. Tetrahedron Lett. 1979, 2965.

149.Gilchrist, T. L.; Wasson, R. C.; King, F. D.; Wootton, G. J. Chem. Soc., Perkin Trans. 1, 1987, 2511-2516.

150.Banert, K.; Hagedorn, M. Tetrahedron Lett. 1992, 33, 7331.

151.Abdelrazek, F.M. Synth. Commun. 2005, 35, 2251.

152.Bondock, S.; Tarhoni, A. E.-G.; Fadda, A.A. ARKIVOC 2006, (ix) 113.

153.Abdelrazek, F. M.; Ghozlan, S. A.; Michael, F. A. J. Heterocyclic Chem. 2007, 44, 63. 
154. Vogeli, U.; von Philipsborn, W. Org. Magn. Reson. 1975, 7, 617.

155.Gregory, B.; Hinz, W.; Jones, R. A.; Sepulveda Arques, J. J. Chem. Res.(S) 1984, 311.

156.US Pat. 4838992; Chem. Abstr. 1990, 112, P7508m.

157.Pal, M.; Batchu, V. R.; Khanna, S.; Yeleswarapu, K. R. Tetrahedron 2002, 58, 9933.

158.Caira, M.R.; Dumitraşcu, F.; Drăghici, C.; Dumitrescu, D.; Cristea, M. Molecules 2005, 10, 360.

159.Mitsumori, T.; Craig, I. M.; Martini, I. B.; Schwartz, B. J.; Wudl, F. Macromolecules 2005, $38,4698$.

160.Vasilescu, M.; Bandula, R.; Cramariuc, O.; Hukka, T.; Lemmetyinen, H.; Rantala, T.T.; Dumitraşcu, F. J. Photochem. Photobiol. A: Chem. 2008, 194, 308.

161.Duffin, G. F. Adv. Heterocycl. Chem. 1977, 2.

162.Jackman, D. E.; Burgstahler, A. W.; Lee, B.; Sheldon, R. I. Cryst. Struct. Commun. 1982, 11,1111 .

163. Galasso, V.; DeAlti, G.; Bigotto, A. Theor. Chim. Acta 1968, 9, 222.

164.Gumba, A.; Farini, G. Gazz. Chim. Ital. 1968, 98, 167.

165.Uhrlandt, E. G.; Clementi, P. H.; Estrada, M. R.; Ponce, C. A. An. Asoc. Quim. Argent. 1990, 78, 1; Chem. Abstr. 1991, 115, 7974x.

166.Maiboroda, D. A.; Babaev, E. V.; Jug, K. J. Org. Chem. 1997, 62, 7100.

167.Parr, R. G.; Yang, W. Density-Functional Theory of Atoms and Molecules; Oxford University Press: New York, 1989.

168.Koch, W.; Holthausen, M.C. A Chemist's guide to density functional theory; Wiley-VCH: Weinheim, 2000.

169.Lee, C.; Yang, W.; Parr, R. G. Phys. Rev. B 1988, 37, 785.

170.Becke, A. D. J. Chem. Phys. 1993, 98, 5648.

171. Matsuo, M.; Manabe, T.; Okumura, H.; Matsuda, H.; Fujii, N. Pat. WO 91/18903, 1991; Chem. Abstr. 1992, 116, P270433a.

172.Ohtani, M.; Fuji, M.; Fukui, Y.; Adachi, M. Pat. WO 9959999, 1999.

173.Fox, B. M.; Iio, K.; Inaba, T.; Kayser, F.; Li, K.; Sagawa, S.; Tanaka, M.; Yoshida, A. US Pat. 7300932, 2003.

174. Salvati, M. E.; Barbosa, S. A.; Chen, Z.; Hunt, J.T. 2003, PCT Int. Appl. WO 2003082208.

175.Salvati, M.E.; Illig, C.R.; Wilson, K.J.; Chen, Z.; Meegalla, S.K.; Wall, M.J. US Patent $7030112,2006$.

176.Fu, J.-M. US Pat. 7074791, 2006. 


\section{Authors' biographies}



Dr. Florea Dumitraşcu was born in 1952. He graduated "Al. I. Cuza" University, Iasi, Romania in 1976. After working for 4 years in industry, he pursued his research interests at the Center for Organic Chemistry "C. D. Nenitzescu”, Romanian Academy, where he obtained his $\mathrm{PhD}$ in 1994. His research interests are in the fields of 1,3-dipolar cycloadditions and heterocyclic chemistry.

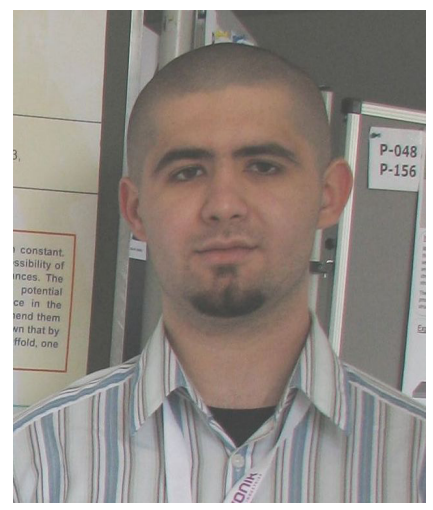

Dan George Dumitrescu was born in 1986 and is currently studying at "Politehnica" University of Bucharest. He has been working as a research assistant with Dr. Florea Dumitraşcu for 3 years and is currently working on his diploma project. 